\title{
A multi-transition molecular line study of candidate massive young stellar objects associated with methanol masers ${ }^{\star}$
}

\author{
M. Szymczak ${ }^{1}$, A. Bartkiewicz ${ }^{1}$, and A. M. S. Richards ${ }^{2}$ \\ 1 Toruń Centre for Astronomy, Nicolaus Copernicus University, Gagarina 11, 87-100 Toruń, Poland \\ e-mail: msz@astro.uni.torun.pl \\ 2 Jodrell Bank Observatory, University of Manchester, Macclesfield, Cheshire SK11 9DL, UK
}

Received 13 February 2007 / Accepted 19 March 2007

\begin{abstract}
Aims. We characterize the molecular environment of candidate massive young stellar objects (MYSOs) signposted by methanol masers.

Methods. Single pixel observations of 10 transitions of $\mathrm{HCO}^{+}, \mathrm{CO}$ and $\mathrm{CS}$ isotopomers were carried out, using the IRAM $30 \mathrm{~m}$ telescope. We studied a sample of 28 targets for which the $6.7 \mathrm{GHz}$ maser emission positions are known with a sub-arcsecond accuracy. Results. The systemic velocity inferred from the optically thin lines agrees within $\pm 3 \mathrm{~km} \mathrm{~s}^{-1}$ with the central velocity of the maser emission for most of the sources. About $64 \%$ of the sources show line wings in one or more transitions of $\mathrm{CO}, \mathrm{HCO}^{+}$and $\mathrm{CS}$ species, indicating the presence of molecular outflows. Comparison of the widths of line wings and methanol maser emission suggests that the $6.7 \mathrm{GHz}$ maser line traces the environment of MYSO of various kinematic regimes. Therefore, conditions conducive for the methanol maser can exist in the inner parts of molecular clouds or circumstellar discs as well as in the outer parts associated with molecular outflows. Calculations of the physical conditions based on the $\mathrm{CO}$ and $\mathrm{HCO}^{+}$lines and the $\mathrm{CS}$ line intensity ratios refine the input parameters for maser models. Specifically, a gas number density of $<10^{7} \mathrm{~cm}^{-3}$ is sufficient for strong maser emission and a high methanol fractional abundance $\left(>5 \times 10^{-7}\right)$ is required.
\end{abstract}

Key words. ISM: molecules - radio lines: ISM - stars: formation - masers

\section{Introduction}

There is compelling evidence that methanol masers are a signature of recent or ongoing high-mass star formation (Menten 1991). However, it is not yet fully understood when they appear in an evolutionary sequence and what they actually trace. The evaporation of grain mantles is postulated as the main process enhancing the fractional abundance of methanol molecules in the gas phase up to $10^{-6}$ (Dartois et al. 1999). This implies that methanol masers can emerge after the formation of an embedded heating source. Methanol maser sources rarely show strong ( $>100 \mathrm{mJy})$ free-free emission at centimetre wavelengths implying that they precede the development of detectable ultra-compact HII (UCHII) region (Walsh et al. 1998; Codella \& Moscadelli 2000). The estimated lifetime of methanol masers is a few $\times 10^{4}$ yr (van der Walt 2005) which is similar to the typical dynamical timescales of molecular outflows. High spatial resolution observations revealed a variety of maser site sizes from 40-1200 AU (e.g. Norris et al. 1998; Walsh et al. 1998; Minier et al.2000). The maser emission arises either from circumstellar discs or behind shocks tracing outflows from massive young stellar objects (MYSOs). No object was found that unequivocally confirms one of these scenarios.

The non-linear nature of maser amplification means that it is difficult to relate the maser line intensity directly to the physical parameters of the active region. Theoretical models predict the formation of methanol maser lines under a rather wide range of

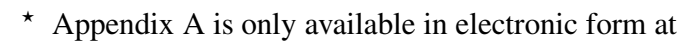
http://www . aanda.org gas and dust temperatures $(30-200 \mathrm{~K}$ and $100-300 \mathrm{~K}$, respectively) and hydrogen number densities $\left(10^{5}-10^{8} \mathrm{~cm}^{-3}\right)$ (Cragg et al. 2002). Thus, it appears that a better understanding of the environments in which the masers arise is required in order to realise their full potential as probes of the formation of highmass stars.

In this paper we report our attempts to constrain the range of environments probed by methanol masers using observations of thermal emission from other molecular species and lines. Specifically, the ratios of the intensities of different transitions of $\mathrm{CS}$ and $\mathrm{C}^{34} \mathrm{~S}$ molecules are used to obtain the temperature and density of the gas. The optically thin and thick lines of $\mathrm{CO}$ and $\mathrm{HCO}^{+}$are used to constrain the column density. These techniques were successfully used to characterize other samples of MYSOs (e.g. Plume et al. 1997; Beuther et al. 2002a; Purcell et al. 2006). Additionally, the molecular line profiles yield information on the kinematics of various parts of the molecular clouds surrounding the high-mass protostars (e.g. Fuller et al. 2005; Purcell et al. 2006).

A homogeneous and unbiased sample of MYSOs is necessary in order to address these issues properly. Our recent 6.7-GHz unbiased survey for methanol masers in selected regions of the Galactic plane (Szymczak et al. 2002) provides such a complete, sensitivity limited sample of candidate MYSOs. Objects identified in the survey probably represent a class of MYSOs in an early evolutionary phase. Some groups and individual sources in this class, selected using various diagnostics of high-mass star formation, have been studied in thermal molecular lines (Brand et al. 2001; Beuther et al. 2002a; 
Table 1. List of targets.

\begin{tabular}{lllllll}
\hline \hline Name & $\alpha(\mathrm{J} 2000)$ & $\delta(\mathrm{J} 2000)$ & $\begin{array}{l}\sigma_{\alpha} \\
(\operatorname{arcsec})\end{array}$ & $\begin{array}{l}\sigma_{\delta} \\
(\operatorname{arcsec})\end{array}$ & $\begin{array}{l}V_{\mathrm{p}} \\
\left(\mathrm{km} \mathrm{s}^{-1}\right)\end{array}$ & $\begin{array}{l}S_{\mathrm{p}} \\
(\mathrm{Jy})\end{array}$ \\
\hline $21.407-0.254$ & 183106.3403 & -102137.305 & 0.28 & 0.80 & +89.0 & 2.0 \\
$22.335-0.155$ & 183229.4109 & -092929.435 & 0.27 & 1.10 & +35.7 & 2.8 \\
$22.357+0.066^{1}$ & 183144.144 & -092212.45 & & & +80. & \\
$23.707-0.198^{3}$ & 183512.3625 & -081739.409 & 0.06 & 0.40 & +79.0 & 3.2 \\
$23.966-0.109^{3}$ & 183522.2167 & -080122.395 & 0.35 & 1.60 & +71.0 & 4.3 \\
$24.147-0.009^{3}$ & 183520.9501 & -074857.470 & 0.03 & 0.19 & +17.9 & 6.4 \\
$24.541+0.312^{3}$ & 183455.7212 & -071906.630 & 0.90 & 0.90 & +105.5 & 4.4 \\
$24.635-0.323$ & 183722.7932 & -073137.950 & 0.50 & 1.20 & +35.5 & 1.0 \\
$25.410+0.105^{2}$ & 183716.9 & -063830.4 & & & +97. & \\
$26.598-0.024$ & 183955.9268 & -053844.490 & 0.03 & 0.18 & +23.0 & 2.0 \\
$27.221+0.136$ & 184030.5446 & -050105.450 & 0.03 & 0.18 & +119.0 & 3.0 \\
$28.817+0.365$ & 184237.3470 & -032941.100 & 0.02 & 0.18 & +91.0 & 1.0 \\
$30.316+0.069$ & 184625.0411 & -021745.160 & 0.03 & 0.16 & +35.5 & 1.3 \\
$30.398-0.297$ & 184752.2623 & -022323.660 & 0.02 & 0.14 & +98.2 & 1.5 \\
$31.056+0.361$ & 184643.8558 & -013015.690 & 0.05 & 0.28 & +81.0 & 1.0 \\
$31.156+0.045$ & 184802.3471 & -013335.095 & 0.10 & 0.90 & +41.0 & 0.8 \\
$31.585+0.080$ & 184841.8975 & -010943.085 & 0.50 & 0.70 & +95.8 & 0.8 \\
$32.966+0.041^{2}$ & 185124.5 & +000433.7 & & & +92. & \\
$33.648-0.224^{3}$ & 185332.5508 & +003206.525 & 0.50 & 1.0 & +62.6 & 20.0 \\
$33.980-0.019$ & 185325.0184 & +005527.260 & 0.05 & 0.50 & +59.0 & 1.0 \\
$34.753-0.092$ & 185505.2410 & +013444.315 & 0.08 & 0.50 & +53.0 & 1.6 \\
$35.791-0.175^{3}$ & 185716.9108 & +022752.900 & 0.04 & 0.17 & +60.8 & 5.6 \\
$36.115+0.552^{3}$ & 185516.8144 & +030503.720 & 0.02 & 0.23 & +74.2 & 7.2 \\
$36.704+0.096$ & 185759.1149 & +032401.395 & 0.08 & 0.17 & +53.0 & 1.9 \\
$37.030-0.039$ & 185903.6435 & +033745.140 & 0.14 & 0.50 & +79.0 & 1.2 \\
$37.479-0.105$ & 190007.1457 & +035953.245 & 0.07 & 0.36 & +62.8 & 1.8 \\
$37.600+0.426$ & 185826.8225 & +042051.770 & 0.03 & 0.70 & +91.2 & 2.0 \\
$39.100+0.491^{3}$ & 190058.0394 & +054243.860 & 0.34 & 0.17 & +15.2 & 2.8 \\
\hline
\end{tabular}

${ }^{1}$ Position is from Walsh et al. (1998); ${ }^{2}$ Position is from Beuther et al. (2002a); ${ }^{3}$ This source was reported in Niezurawska et al. (2005).

Fuller et al. 2005), but this is the first published study of a homogeneous sample based solely on the presence of detectable methanol masers.

\section{The sample}

The 28 sources observed in this study (Table 1) were chosen from a sample of 100 methanol maser sources found in the Torun $32 \mathrm{~m}$ telescope blind survey for the $6.7 \mathrm{GHz}$ methanol line in the Galactic plane area $20^{\circ} \leq l \leq 40^{\circ}$ and $|b| \leq 0.52$ (Szymczak et al. 2002). This flux-limited ( $3 \sigma \simeq 1.6 \mathrm{Jy}$ ) subsample includes 25 out of 26 sources which were undetected prior to the Torun survey. Therefore, our subsample specifically excludes previously known sources associated with $\mathrm{OH}$ maser emission (Caswell et al. 1995) or with IRAS-selected bright UCHII candidates (Schutte et al. 1993; van der Walt et al. 1995; Walsh et al. 1997). Assuming that $\mathrm{CH}_{3} \mathrm{OH}$ masing precedes the appearance of $\mathrm{OH}$ masers and detectable UCHII regions, the objects studied here represent sites of high-mass star formation at a very early stage. The average peak maser flux of the 28 targets is $17.3 \mathrm{Jy}$, a factor of 2.6 lower than that of the other 72 objects in the original sample, suggesting that distant or intrinsically faint objects may be over-represented in our subsample. The subsample studied here is most certainly not complete.

\subsection{Astrometric positions}

The coordinates and position uncertainties of the brightest 6.7-GHz maser component in each source are presented in Table 1 . The LSR velocity of this component $\left(V_{\mathrm{p}}\right)$ and its peak flux density $\left(S_{\mathrm{p}}\right)$ are given for each target. The positions and flux densities of all but three objects were measured with the Mark II - Cambridge baseline of MERLIN in two sessions between 2002 May and 2003 May. For the three objects not measured the peak velocities were taken from Szymczak et al. (2002).

The observational setup and data reduction were described in Niezurawska et al. (2005). A primary goal of those astrometric measurements was to determine the positions with sub-arcsecond accuracy for follow-up VLBI observations. Measurement errors mainly depended upon the ratio of the beam size to the signal to the noise ratio (Thompson et al. 1991). If the emission was complex we took the dispersion of neighbouring maxima as the position uncertainty. The $\mathrm{N}-\mathrm{S}$ elongation of the synthesized beam close to declination $0^{\circ}$ produces a split peak, in which case the position uncertainty in that direction was taken as half the separation of the maxima. Consequently, for sources with a single clear peak, the position errors in right ascension were as small as $0 \prime^{\prime} 02$ but increased up to 0.90 for sources with complex emission. The respective errors in the declination were 0 .' 14 and 1'.6. Comparison with our unpublished VLBI observations reveals position differences between MERLIN and VLBI measurements no worse than a few tens of milli-arcseconds. This implies that the values listed in Table 1 are maximal position errors for most of the targets. The flux densities listed in Table 1 are a factor of 2-3 lower than those measured with the single dish (Szymczak et al. 2002) and should be considered as lower limits. The exact flux scale and gainelevation effects for low-declination sources are not yet fully investigated at $6 \mathrm{GHz}$ but comparison of calibration sources in common with other experiments shows that the uncertainties 
are $10-\leq 50 \%$. This suggests that about half the methanol flux arises on scales larger than the beam size of 50-100 mas.

\subsection{Distances}

The distances were determined using the Galactic rotation curve of Brand \& Blitz (1993) and the central velocity of each $6.7 \mathrm{GHz}$ methanol maser profile as measured by Szymczak et al. (2002). Selection of this velocity as a reliable estimator of the systemic velocity is proven in Sect. 6.1. The sources are all in the first quadrant so that there is an ambiguity between the near and far kinematic distances. In most cases we are unable to resolve this ambiguity because there are no independent distance measurements in the literature for our sample. Based on the arguments discussed in Walsh et al. (1997), we adopted the near kinematic distances (Table 4).

\section{Observations and data reduction}

Observations were carried out between 2004 September 28 and October 2 with the IRAM $30 \mathrm{~m}$ telescope. Ten transitions of $\mathrm{HCO}^{+}, \mathrm{CO}$ and $\mathrm{CS}$ isotopomers were observed. Two or three SIS receivers tuned to single sideband mode were used simultaneously, in combination with the VESPA autocorrelator as well as with $100 \mathrm{kHz}$ and $1 \mathrm{MHz}$ filter banks. Table 2 lists the rest line frequencies, half power beam widths (HPBWs), velocity resolutions and typical system temperatures for each transition.

The data were taken using the position switching mode. The off positions were typically $30^{\prime}$ away from the targets. In the few cases, especially for the $\mathrm{C}^{13} \mathrm{O} J=2-1$ line, where emission was seen at the reference position, the offsets were increased up to $45^{\prime}$ in the direction away from the Galactic plane. The observations were centered on the target positions listed in Table 1. Integration times on-source in total power mode were $12-18 \mathrm{~min}$ per frequency setting, resulting in $\mathrm{rms}$ noise levels ranging from $\approx 0.05 \mathrm{~K}$ at $87 \mathrm{GHz}$ to $\approx 0.90 \mathrm{~K}$ at $245 \mathrm{GHz}$ for a spectral resolution of $0.10-0.16 \mathrm{~km} \mathrm{~s}^{-1}$. Pointing was checked regularly on nearby continuum sources and was usually found to be within $2^{\prime \prime}$ and always within $3^{\prime \prime}$. The spectra were scaled to the main beam brightness temperature $\left(T_{\mathrm{mb}}\right)$ using the efficiencies supplied by the observatory ${ }^{1}$. Comparison of our data with those taken by Brand et al. (2001) with the same telescope and spectral resolutions for a source in common, $36.115+0.552$, implies consistent intensity scales within less than $30 \%$.

The data reduction was performed using the CLASS software package. Low order polynomials were applied to remove baselines from the calibrated spectra. The line parameters were determined from Gaussian fits and are listed in Table A.1 where the following information is given: the rms $(1 \sigma)$ noise level, the extreme velocities $V_{\mathrm{s}}, V_{\mathrm{e}}$ where the intensity drops below the $2 \sigma$ level, the peak temperature $T_{\mathrm{mb}}$, the velocity of the peak $V_{\mathrm{p}}$, the line width at half maximum $\Delta V$ and the integrated line intensity $\int T_{\mathrm{mb}} \mathrm{d} v$. Velocities are in the LSR frame. In several cases where the profiles were non-Gaussian, these values were read off from the spectra. In some cases the spectra were smoothed to improve the signal to noise ratio. In this paper, only the autocorrelation spectra are analyzed.

\footnotetext{
1 http://wWw.iram.es/IRAMES/telescope/ telescopeSummary/telescope_summary.html
}

Table 2. Observing parameters.

\begin{tabular}{lrcccr}
\hline \hline Transition & $\begin{array}{c}\text { Frequency } \\
(\mathrm{GHz})\end{array}$ & Ref. & $\begin{array}{c}H P B W \\
\left({ }^{\prime \prime}\right)\end{array}$ & $\begin{array}{c}\text { Res. } \\
\left(\mathrm{km} \mathrm{s}^{-1}\right)\end{array}$ & $\begin{array}{c}T_{\text {sys }} \\
(\mathrm{K})\end{array}$ \\
\hline $\mathrm{HCO}^{+}(1-0)$ & 89.188518 & 2 & 27 & 0.13 & 200 \\
$\mathrm{H}^{13} \mathrm{CO}^{+}(1-0)$ & 86.754330 & 1 & 27 & 0.13 & 200 \\
${ }^{13} \mathrm{CO}(2-1)$ & 220.398686 & 2 & 11 & 0.11 & 1200 \\
$\mathrm{C}^{18} \mathrm{O}(2-1)$ & 219.560328 & 2 & 11 & 0.11 & 1340 \\
$\mathrm{CS}(2-1)$ & 97.980953 & 1 & 25 & 0.12 & 260 \\
$\mathrm{CS}(3-2)$ & 146.969049 & 2 & 17 & 0.16 & 690 \\
$\mathrm{CS}(5-4)$ & 244.935560 & 1 & 10 & 0.10 & 1830 \\
$\mathrm{C}^{34} \mathrm{~S}(2-1)$ & 96.412961 & 1 & 25 & 0.12 & 290 \\
$\mathrm{C}^{34} \mathrm{~S}(3-2)$ & 144.617147 & 2 & 17 & 0.16 & 560 \\
$\mathrm{C}^{34} \mathrm{~S}(5-4)$ & 241.016113 & 1 & 10 & 0.10 & 2100 \\
\hline
\end{tabular}

The references for the line frequencies are 1 - Lovas (2003); 2 - Brand et al. (2001).

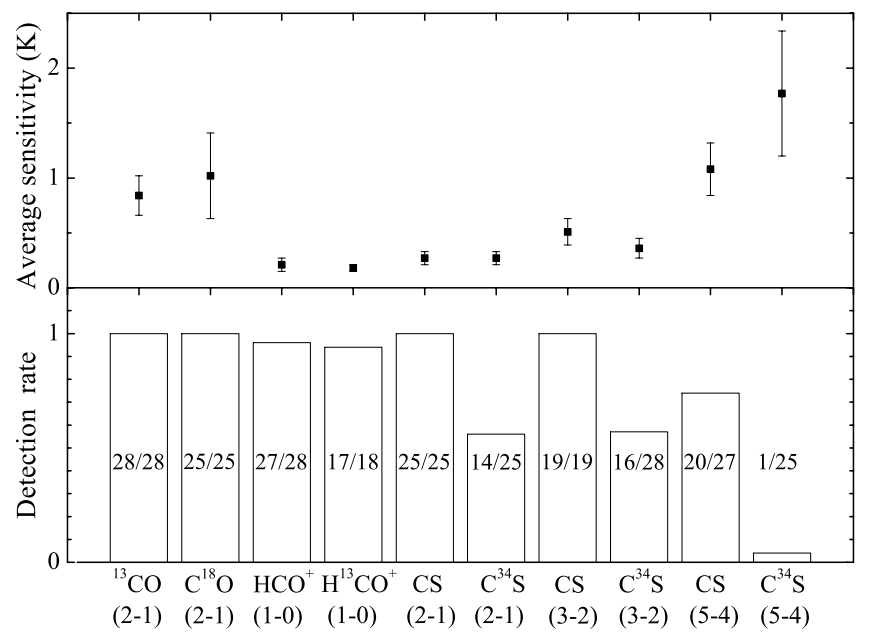

Fig. 1. The average sensitivity achieved for each transition (top) and the detection rate (bottom). The ratio of the number of detected to observed objects is shown in each of the bars.

\section{Results}

The basic parameters of molecular transitions derived from Gaussian analysis are assembled in Table A.1, while the spectra are shown in Fig. A.1.

The sensitivity achieved and detection rate for each transition are summarized in Fig. 1. The histogram counts as detected only those lines with $T_{\mathrm{mb}}>3 \sigma \cdot{ }^{13} \mathrm{CO}(2-1), \mathrm{C}^{18} \mathrm{O}(2-1), \mathrm{CS}(2-1)$ and $\mathrm{CS}(3-2)$ lines were detected in all sources. $\mathrm{HCO}^{+}(1-0)$ and $\mathrm{H}^{13} \mathrm{CO}^{+}(1-0)$ lines were detected in all but one source. The detection rates in $\mathrm{C}^{34} \mathrm{~S}(2-1)$ and $\mathrm{C}^{34} \mathrm{~S}(3-2)$ transitions were about half of those in $\operatorname{CS}(2-1)$ and $\operatorname{CS}(3-2)$ lines. Because the sensitivities achieved for these four lines were comparable, these detection rate differences reflect a real drop in the number of sources exhibiting emission at the same level in the $\mathrm{C}^{34} \mathrm{~S}(2-1)$ and $C^{34} S(3-2)$ lines. In contrast, the lower detection rates in the $\mathrm{CS}(5-4)$ and $\mathrm{C}^{34} \mathrm{~S}(5-4)$ transitions appear to reflect the drop in sensitivity.

\subsection{Systemic velocities}

Five of the observed lines $\left(\mathrm{C}^{18} \mathrm{O}(2-1), \mathrm{H}^{13} \mathrm{CO}^{+}(1-0)\right.$ and the $J=2-1,3-2$ and 5-4 transitions of $\left.\mathrm{C}^{34} \mathrm{~S}\right)$ are expected to be optically thin (Plume et al. 1997; Brand et al.2001; Purcell et al. 2006). These lines can be used to determine source systemic velocities. In order to test whether these species trace the 
same or similar kinematic regimes we compare their line parameters. The $\mathrm{C}^{34} \mathrm{~S}(5-4)$ line is excluded from the following analysis due to very low number of detections.

The average intensities of the $\mathrm{H}^{13} \mathrm{CO}^{+}(1-0)$ and $\mathrm{C}^{34} \mathrm{~S}$ lines are very similar and are a factor of 8 weaker than the average intensity of the $\mathrm{C}^{18} \mathrm{O}(2-1)$ line. This implies that the parameters of the latter line, especially $V_{\mathrm{p}}$, are determined most accurately.

We note that some line rest frequencies adopted from Brand et al. (2001) differ slightly from those recommended by Lovas (2003). In the extreme case of $C^{34} S(3-2)$ this results in the velocity difference of $0.07 \mathrm{~km} \mathrm{~s}^{-1}$. Moreover, the uncertainties in the line rest frequencies introduce a maximum uncertainty of $\pm 0.17 \mathrm{~km} \mathrm{~s}^{-1}$ to the derived line velocity for the $\mathrm{H}^{13} \mathrm{CO}^{+}(1-0)$. We assume that the above uncertainties affect the velocity estimates by up to $0.24 \mathrm{~km} \mathrm{~s}^{-1}$. Comparison of the velocities of the four optically thin lines in our sample reveals no significant average differences higher than $0.30 \mathrm{~km} \mathrm{~s}^{-1}$. This suggests the same kinematic behaviour of these low-density gas tracers.

At $100 \mathrm{~K}$ the thermal linewidths of $\mathrm{C}^{18} \mathrm{O}(2-1)$ and $\mathrm{H}^{13} \mathrm{CO}^{+}(1-0)$ are $0.24 \mathrm{~km} \mathrm{~s}^{-1}$ whereas those of $\mathrm{C}^{34} \mathrm{~S}(2-1)$ and $\mathrm{C}^{34} \mathrm{~S}(3-2)$ are $0.20 \mathrm{~km} \mathrm{~s}^{-1}$. The observed linewidths are much broader, suggesting that turbulence or bulk gas motions play a significant role in the line broadening. The mean linewidth ratios of the optically thin lines are 5-10\% higher than unity. This bias is relatively small and suggests that the lines trace the same molecular gas in the beam. The systemic velocities are listed in Table 4. They are primarily the $C^{34} S(2-1)$ and $C^{34} S(3-2)$ line peak velocities. If emission in these lines is absent or weak the other optically thin lines are used. In two sources, $37.030-0.039$ and $37.600+0.426$, the systemic velocities are derived from $\mathrm{CS}(5-4)$ and $\mathrm{HCO}^{+}(1-0)$ profiles, respectively. We conclude that in most cases the observed optically thin lines are well fitted by single Gaussian profiles (deviations are discussed in Sect. 4.2.2) and their peak velocities are within $\pm 0.4 \mathrm{~km} \mathrm{~s}^{-1}$ of each other for almost all sources in the sample. Therefore, these lines provide reliable estimates of systemic velocity of sufficient accuracy to allow comparison with the methanol maser velocities listed in Szymczak et al. (2002).

\subsection{Shape of profiles}

We analyse the molecular line profiles in order to search for specific signatures of ordered motions such as infall, outflow or rotation. Inward motion can be signposted by blue asymmetric profiles (Myers et al. 1996; Fuller et al. 2005) if the molecular spectral lines trace sufficiently dense gas. Signatures of outflow or rotation are generally manifested in the line wings.

\subsubsection{Asymmetry}

We analysed line asymmetry quantitatively using the asymmetry parameter (Mardones et al. 1997), $\delta v=\left(v_{\text {thick }}-v_{\text {thin }}\right) / \Delta V_{\text {thin }}$, where $v_{\text {thick }}$ and $v_{\text {thin }}$ are the peak velocities of optically thick and optically thin lines, respectively and $\Delta V_{\text {thin }}$ is the line width at half maximum of the optically thin line. We used $\mathrm{C}^{34} \mathrm{~S}(2-1)$ as the optically thin line and the best available measure of the systemic velocity of MYSOs. Figure 2 shows histograms of the distribution of $\delta v$ for the optically thick lines ${ }^{13} \mathrm{CO}(2-1)$, $\mathrm{HCO}^{+}(1-0), \mathrm{CS}(2-1), \mathrm{CS}(3-2)$ and $\mathrm{CS}(5-4)$. There are approximately equal numbers of blue and red asymmetric profiles in our sample. Specifically, we note that there is no evidence for an excess of blue-shifted emission in the optically thick lines.

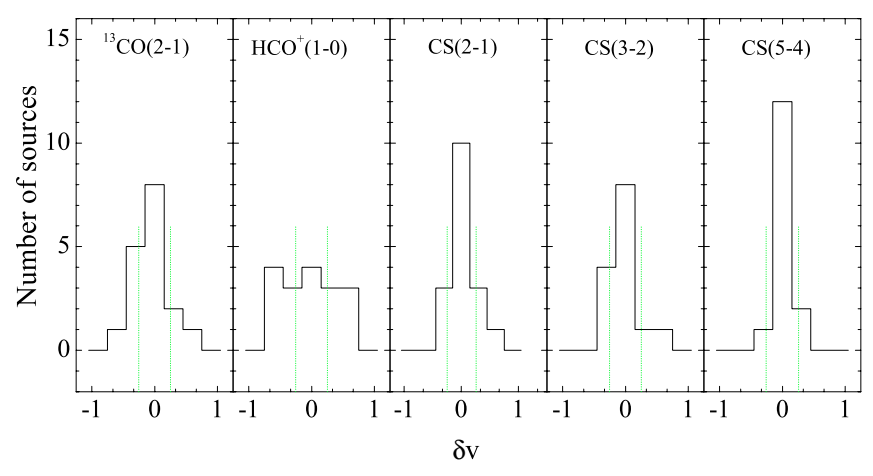

Fig. 2. Histograms of the distribution of the asymmetry parameter $\delta v$ for the five transitions. The range of $|\delta v|<0.25$ marked by the dotted lines corresponds to the spectra with no asymmetry.

Such an excess is postulated as the signature of inward motion of the gas (Myers et al. 1996). We suggest that motions other than infall, i.e. turbulence, rotation and outflow, are the dominant factor producing asymmetric profiles for most of the sources in our sample. It is possible that infall signatures could be masked by the relatively low resolution (typically $\geq 0.2 \mathrm{pc}$, i.e. at a distance of $5 \mathrm{kpc}$ and spatial resolution of $10^{\prime \prime}$ ) of our observations, since even the near kinematic distances are $>3 \mathrm{kpc}$ for $\sim 80 \%$ of the sources (the average $D_{\text {near }}$ is $5.2 \pm 2.5 \mathrm{kpc}$ for the whole sample).

We therefore examined separately the 5 closest $\left(D_{\text {near }}<\right.$ $2.8 \mathrm{kpc}$ ) objects with well-determined asymmetry parameters. Two of these, 26.598-0.024 and 30.316+0.069, consistently show negative values of $\delta v$, i.e. blue asymmetry, in the ${ }^{13} \mathrm{CO}(2-1), \mathrm{HCO}^{+}(1-0), \mathrm{CS}(2-1)$ and $\mathrm{CS}(3-2)$ line profiles (Fig. A.1). The corresponding values of $\delta v$ are $-0.38,-0.82$, -0.15 and -0.18 for source $26.598-0.024$ and $-0.43,-0.60$, -0.33 and -0.37 for source $30.316+0.069$. Their asymmetry parameters are smaller for the optically thin lines (i.e. $\mathrm{C}^{18} \mathrm{O}(2-1)$ and $\left.\mathrm{H}^{13} \mathrm{CO}^{+}(1-0)\right)$, in the range from -0.20 to 0.0 . Such a dependence of the amount of blue asymmetry on the optical depth of the transition is typical in molecular cores experiencing infall (Narayanan et al. 1998). We suggest that these two sources are the clearest infall candidates although source complexity or a combination of outflow and rotation could contribute to asymmetries in optically thick profiles.

\subsubsection{Wings}

Wing emission is identified by the presence of residuals after Gaussian fitting and by comparing the same transitions of optically thick and thin isotopomers. A single Gaussian function provides a good fit to most of the optically thin lines analyzed in Sect. 4.1, but in a few cases the residuals are at a level $\geq 3 \sigma$, assumed to be wing emission. We cannot exclude the possibility that they are weak separate component(s), given the limitations of our signal to noise ratio and spectral resolution, but we note that the blue and/or red residuals are non-Gaussian in most cases. 4 out of 25 sources detected in the $\mathrm{C}^{18} \mathrm{O}(2-1)$ line show weak $(3-4 \sigma)$ wing emission of width $4.5-8 \mathrm{~km} \mathrm{~s}^{-1}$ (Table 3) which mostly is seen from the red or blue sides of the profiles. In the $\mathrm{H}^{13} \mathrm{CO}^{+}(1-0)$ line the wing emission is seen in 2 out of 17 objects detected (Table 3). $25.410+0.105$ is a peculiar source showing broad $\left(7-8 \mathrm{~km} \mathrm{~s}^{-1}\right)$ and symmetric wings in both lines (Fig. A.1).

In contrast, the optically thick lines show more frequent absorption dips, multiple components and wings. In several 
Table 3. Statistics of wing occurrence. Entries marked $\mathrm{Y}$ or $\mathrm{N}$ indicate symmetric wings and no wings respectively, $\mathrm{Yb}$ or $\mathrm{Yr}$ indicate wing emission seen from the blue and red sides of the profiles, respectively. An interrogation point (?) indicates a tentative wing and the absence of entry indicates no observation.

\begin{tabular}{lcccccc}
\hline \hline Source & $\mathrm{C}^{18} \mathrm{O}$ & $\mathrm{H}^{13} \mathrm{CO}^{+}$ & ${ }^{13} \mathrm{CO}$ & $\mathrm{HCO}^{+}$ & $\mathrm{CS}$ & $\mathrm{CS}$ \\
$(2-1)$ & $(1-0)$ & $(2-1)$ & $(1-0)$ & $(2-1)$ & $(3-2)$ \\
\hline $21.407-0.254$ & $\mathrm{~N}$ & & $\mathrm{~N}$ & & $\mathrm{~N}$ & \\
$22.335-0.155$ & $\mathrm{~N}$ & $\mathrm{~N}$ & $\mathrm{~N}$ & $\mathrm{Y}$ & $\mathrm{N}$ & $\mathrm{N}$ \\
$22.357+0.066$ & $\mathrm{Yb}$ & $\mathrm{N}$ & $\mathrm{N}$ & $\mathrm{N}$ & $\mathrm{N}$ & $\mathrm{N}$ \\
$23.707-0.198$ & $\mathrm{~N}$ & $\mathrm{~N}$ & $\mathrm{~N}$ & $\mathrm{~N}$ & $\mathrm{~N}$ & $\mathrm{~N}$ \\
$23.966-0.109$ & $\mathrm{~N}$ & $\mathrm{Yr}$ & $\mathrm{N}$ & $\mathrm{Y}$ & $\mathrm{Y}$ & $\mathrm{Y}$ \\
$24.147-0.009$ & $\mathrm{~N}$ & $\mathrm{~N}$ & $\mathrm{~N}$ & $\mathrm{Y}$ & $\mathrm{N}$ & $\mathrm{N}$ \\
$24.541+0.312$ & $\mathrm{Y}$ & $\mathrm{N}$ & $\mathrm{N}$ & $\mathrm{Y}$ & $\mathrm{N}$ & $\mathrm{N}$ \\
$24.635-0.323$ & $\mathrm{Yr}$ & $\mathrm{N}$ & $\mathrm{Y}$ & $\mathrm{Y}$ & $\mathrm{Y}$ & $\mathrm{Y}$ \\
$25.410+0.105$ & $\mathrm{~N}$ & $\mathrm{Y}$ & $\mathrm{Y}$ & $\mathrm{Y}$ & $\mathrm{Y}$ & $\mathrm{Y}$ \\
$26.598-0.024$ & $\mathrm{~N}$ & $\mathrm{~N}$ & $\mathrm{~N}$ & $\mathrm{~N}$ & $\mathrm{~N}$ & $\mathrm{~N}$ \\
$27.221+0.136$ & $\mathrm{~N}$ & & $\mathrm{~N}$ & $\mathrm{~N}$ & $\mathrm{~N}$ & \\
$28.817+0.365$ & $\mathrm{~N}$ & & $\mathrm{~N}$ & $\mathrm{Y}$ & $\mathrm{Y}$ & \\
$30.316+0.069$ & $\mathrm{~N}$ & $\mathrm{~N}$ & $\mathrm{~N}$ & $\mathrm{Y}$ & $\mathrm{N}$ & $\mathrm{N}$ \\
$30.398-0.297$ & $\mathrm{Yb}$ & $\mathrm{N}$ & $?$ & $\mathrm{Y}$ & $\mathrm{Y}$ & $\mathrm{N}$ \\
$31.056+0.361$ & $\mathrm{~N}$ & & $\mathrm{~N}$ & $\mathrm{~N}$ & $\mathrm{~N}$ & \\
$31.156+0.045$ & $\mathrm{~N}$ & $\mathrm{~N}$ & $?$ & $\mathrm{Y}$ & $\mathrm{Y}$ & $\mathrm{Y}$ \\
$31.585+0.080$ & $\mathrm{~N}$ & & $\mathrm{~N}$ & $\mathrm{~N}$ & $\mathrm{~N}$ & \\
$32.966+0.041$ & $\mathrm{~N}$ & $\mathrm{~N}$ & $?$ & $\mathrm{~N}$ & $\mathrm{~N}$ & $\mathrm{~N}$ \\
$33.648-0.224$ & $\mathrm{~N}$ & & $\mathrm{~N}$ & $\mathrm{~N}$ & $\mathrm{~N}$ & $\mathrm{~N}$ \\
$33.980-0.019$ & $\mathrm{~N}$ & $\mathrm{~N}$ & $\mathrm{~N}$ & $\mathrm{Y}$ & $\mathrm{Y}$ & $\mathrm{Y}$ \\
$34.753-0.092$ & $\mathrm{~N}$ & & $?$ & $\mathrm{Y}$ & $\mathrm{N}$ & \\
$35.791-0.175$ & $\mathrm{~N}$ & $\mathrm{~N}$ & $?$ & $\mathrm{Y}$ & $\mathrm{Y}$ & $\mathrm{Y}$ \\
$36.115+0.552$ & $\mathrm{~N}$ & $\mathrm{~N}$ & $\mathrm{~N}$ & $\mathrm{Y}$ & $\mathrm{N}$ & $\mathrm{N}$ \\
$36.704+0.096$ & $\mathrm{~N}$ & & $\mathrm{~N}$ & $\mathrm{Y}$ & $\mathrm{N}$ & $\mathrm{N}$ \\
$37.030-0.039$ & & & $\mathrm{~N}$ & $\mathrm{~N}$ & & \\
$37.479-0.105$ & & & $?$ & $\mathrm{~N}$ & & \\
$37.600+0.426$ & & & $\mathrm{Y}$ & $\mathrm{Y}$ & & \\
$39.100+0.491$ & $\mathrm{~N}$ & $\mathrm{~N}$ & $\mathrm{~N}$ & $\mathrm{Y}$ & $\mathrm{Y}$ & $\mathrm{Y}$ \\
\hline & & & & & &
\end{tabular}

cases identification of the wings is difficult. The ${ }^{13} \mathrm{CO}(2-1)$ profiles are especially complex; commonly they are fit by 2-5 Gaussians. These profiles can be interpreted as multiple emitting regions along the same line of sight. The ${ }^{13} \mathrm{CO}(2-1)$ lines show evidence of wings in only 3 objects (Table 3 ).

The $\mathrm{HCO}^{+}(1-0)$ lines are also complex, often exhibiting two or more components or broad line wings (Fig. A.1). They appear to consist of the superposition of several emitters seen along the line of sight or of (self)absorption by cooler gas on the near side of the source. Wings are identified in 17 out of 27 detections (Table 4). The wing full width ranges from 6 to $20 \mathrm{~km} \mathrm{~s}^{-1}$ with a mean value of $10.3 \pm 3.3 \mathrm{~km} \mathrm{~s}^{-1}$.

Evidence for wings is seen in the $\mathrm{CS}(2-1)$ transition for 9 out of 25 sources and in the $\operatorname{CS}(3-2)$ transition for 7 out of 19 sources (Table 3 ). Their full widths are from 8 to $19 \mathrm{~km} \mathrm{~s}^{-1}$.

We conclude that $64 \%(18 / 28)$ of the sources show residual line wings at least in one line when a Gaussian profile is used to fit the $\mathrm{CO}, \mathrm{HCO}^{+}$and $\mathrm{CS}$ molecular lines. Detection of the wings may indicate molecular outflows from the MYSOs identified by methanol masers but we caution that such detections based on our data alone are only tentative.

\section{Derivation of physical parameters}

\subsection{Column densities}

In order to estimate the column density of $\mathrm{H}^{13} \mathrm{CO}^{+}$from the observed $\mathrm{HCO}^{+}(1-0)$ and $\mathrm{H}^{13} \mathrm{CO}^{+}(1-0)$ line parameters, we follow the procedure outlined in Purcell et al. (2006) and references therein. Briefly, the main assumptions made are: (i) $\mathrm{HCO}^{+}(1-0)$ is optically thick and $\mathrm{H}^{13} \mathrm{CO}^{+}(1-0)$ is optically thin. (ii) Both lines form in the same gas and share the same excitation temperature. (iii) The excitation temperature is equal to the rotational temperature. (iv) The gas is in local thermodynamic equilibrium. (v) The beam filling factor is one for both lines.

The derived $\mathrm{H}^{13} \mathrm{CO}^{+}$column density, $N\left(\mathrm{H}^{13} \mathrm{CO}^{+}\right)$, (Table 4) ranges from $1.3-5.1 \times 10^{12} \mathrm{~cm}^{-2}$ and the median value is $2.2 \times 10^{12} \mathrm{~cm}^{-2}$. We derive a value of $N\left(\mathrm{H}^{13} \mathrm{CO}^{+}\right)$a factor of 4 smaller than the value found by Purcell et al. (2006) for two of the sources common to both samples, 22.357+0.066 and 23.707-0.198. This is probably because Purcell et al. applied corrections for self-absorption, leading to higher estimates of the $\mathrm{HCO}^{+}(1-0)$ line intensities and lower optical depths, compared with our study. We adopt an abundance ratio of $\left[\mathrm{H}^{13} \mathrm{CO}^{+}\right] /\left[\mathrm{H}_{2}\right]=3 \times 10^{-11}$ (Girart et al. 2000), from which we obtain the $\mathrm{H}_{2}$ column density from $4.3-17.0 \times 10^{22} \mathrm{~cm}^{-2}$ with the median value of $7.3 \times 10^{22} \mathrm{~cm}^{-2}$.

We apply the same method to estimate the column density of $\mathrm{C}^{18} \mathrm{O}, N\left(\mathrm{C}^{18} \mathrm{O}\right)$, from the line parameters of ${ }^{13} \mathrm{CO}(2-1)$ and $\mathrm{C}^{18} \mathrm{O}(2-1)$, assuming that ${ }^{13} \mathrm{CO}(2-1)$ is optically thick and $\mathrm{C}^{18} \mathrm{O}(2-1)$ is optically thin. For our sample $N\left(\mathrm{C}^{18} \mathrm{O}\right)$ is $0.9-32.6 \times 10^{15} \mathrm{~cm}^{-2}$ (Table 4) with the median value of $4.6 \times$ $10^{15} \mathrm{~cm}^{-2}$. The temperature varies between 10 and $30 \mathrm{~K}$. The resulting $\mathrm{H}_{2}$ column density ranges from $5.4 \times 10^{21}-1.9 \times 10^{23} \mathrm{~cm}^{-2}$ for an abundance ratio $\left[\mathrm{C}^{18} \mathrm{O}\right] /\left[\mathrm{H}_{2}\right]=1.7 \times 10^{-7}$ (Frerking et al. 1982).

We conclude that the $\mathrm{CO}$ and $\mathrm{HCO}^{+}$data provide consistent estimates of the column density of $\mathrm{H}_{2}$ towards the methanol maser sources. The range of $N\left(\mathrm{H}_{2}\right)$ derived here is in good agreement with that reported for high-mass protostar candidates associated with methanol masers; $3 \times 10^{22}-2 \times 10^{23} \mathrm{~cm}^{-2}$ (Codella et al. 2004; Minier et al. 2005; Purcell et al. 2006). However, it is significantly lower than $N\left(\mathrm{H}_{2}\right) \geq 4 \times 10^{23} \mathrm{~cm}^{-2}$ reported in some earlier works (e.g. Churchwell et al. 1992) for ultracompact HII regions. This discrepancy is likely due to the temperatures of $10-30 \mathrm{~K}$ derived here which is significantly lower than $\geq 100 \mathrm{~K}$ assumed in Churchwell et al. (1992).

We notice that a dispersion of the $N\left(\mathrm{C}^{18} \mathrm{O}\right)$ is a factor of 7 larger than that of the $N\left(\mathrm{H}^{13} \mathrm{CO}^{+}\right)$(Table 4). In two sources $22.357+0.066$ and $26.598-0.024$ the $N\left(\mathrm{C}^{18} \mathrm{O}\right)$ is extremely large $\left(>1.9 \times 10^{16} \mathrm{~cm}^{-2}\right)$. In consequence, the values of $N\left(\mathrm{H}_{2}\right)$ derived from the $\mathrm{C}^{18} \mathrm{O}$ is a factor of 1.5 and 3.1 , respectively, higher that those derived from the $\mathrm{H}^{13} \mathrm{CO}^{+}$. This discrepancy suggests that the methanol masers in these sources probe regions with the abundance ratio of ${ }^{13} \mathrm{CO} / \mathrm{C}^{18} \mathrm{O}$ significantly lower than a typical ratio of 6.5-7 (Frerking et al. 1982; Beuther et al.2000). A decrease of ${ }^{13} \mathrm{CO} / \mathrm{C}^{18} \mathrm{O}$ ratio is predicted in the PDR model in a clumpy cloud; in small clumps the $\mathrm{C}^{18} \mathrm{O}$ molecule is nearly completely photodissociated whilst it is protected from photodissociation in large clumps (Beuther et al. 2000, and references therein). Object 26.598-0.024 with the highest value of $N\left(\mathrm{C}^{18} \mathrm{O}\right)$ is also a candidate infall object (Sect. 4.2.1) and one can speculate that it is the youngest methanol maser in our sample; the maser emission forms in large clumps at nearly systemic velocity. Another explanation of low ${ }^{13} \mathrm{CO} / \mathrm{C}^{18} \mathrm{O}$ intensity ratio can be that our $11^{\prime \prime}$ beam probes the methanol maser sites where the $\mathrm{C}^{18} \mathrm{O}$ cores did not coincide with the ${ }^{13} \mathrm{CO}$ cores. This observational fact is well documented in Brand et al. (2001) at least for their sources Mol 98 and Mol 136 (see their Fig. 5). Furthermore, the $\mathrm{C}^{18} \mathrm{O}$ emission is less extended than the ${ }^{13} \mathrm{CO}$ emission; by a factor of $\sim 3-5$ for common source $35.791-0.175$. This explanation seems to be 
Table 4. Derived properties.

\begin{tabular}{|c|c|c|c|c|c|c|c|c|c|}
\hline \multirow[b]{2}{*}{ Source } & \multirow[b]{2}{*}{$\begin{array}{l}V_{\text {sys }} \\
\left(\mathrm{km} \mathrm{s}^{-1}\right)\end{array}$} & \multirow[b]{2}{*}{$\begin{array}{l}d_{\text {near }} \\
(\mathrm{kpc})\end{array}$} & \multirow[b]{2}{*}{$\begin{array}{l}d_{\text {far }} \\
(\mathrm{kpc})\end{array}$} & \multirow[b]{2}{*}{$\begin{array}{c}N\left(\mathrm{H}^{13} \mathrm{CO}^{+}\right) \\
\left(10^{12} \mathrm{~cm}^{-2}\right)\end{array}$} & \multirow[b]{2}{*}{$\begin{array}{c}N\left(\mathrm{C}^{18} \mathrm{O}\right) \\
\left(10^{15} \mathrm{~cm}^{-2}\right)\end{array}$} & \multicolumn{2}{|c|}{$30 \mathrm{~K}$} & \multicolumn{2}{|c|}{$60 \mathrm{~K}$} \\
\hline & & & & & & $\begin{array}{l}\log n_{\mathrm{H}_{2}} \\
\left(\mathrm{~cm}^{-3}\right)\end{array}$ & $\begin{array}{c}\log N(\mathrm{CS}) \\
\left(\mathrm{cm}^{-2}\right)\end{array}$ & $\begin{array}{l}\log n_{\mathrm{H}_{2}} \\
\left(\mathrm{~cm}^{-3}\right)\end{array}$ & $\begin{array}{c}\log N(\mathrm{CS}) \\
\left(\mathrm{cm}^{-2}\right)\end{array}$ \\
\hline $21.407-0.254$ & 90.7 & 6.0 & 10.4 & - & 3.8 & - & - & - & - \\
\hline $22.335-0.155$ & 30.9 & 2.4 & 14.7 & 2.1 & 3.7 & $6.15 \pm 0.15$ & $14.52 \pm 0.10$ & $5.91 \pm 0.12$ & $14.68 \pm 0.06$ \\
\hline $22.357+0.066$ & 84.2 & 5.2 & 10.6 & 2.2 & 19.1 & $5.48 \pm 0.09$ & $14.70 \pm 0.11$ & $5.27 \pm 0.13$ & $14.52 \pm 0.21$ \\
\hline $23.707-0.198$ & 68.9 & 5.1 & 10.5 & 3.2 & 13.2 & $5.93 \pm 0.08$ & $13.74 \pm 0.14$ & $5.57 \pm 0.08$ & $13.49 \pm 0.07$ \\
\hline $23.966-0.109$ & 72.7 & 4.2 & 11.6 & 5.1 & 9.0 & $>6.7$ & $14.73 \pm 0.57$ & $>6.5$ & $15.16 \pm 0.52$ \\
\hline $24.147-0.009$ & 23.1 & 2.0 & 14.5 & 1.4 & 2.1 & $5.61 \pm 0.08$ & $14.51 \pm 0.18$ & $5.42 \pm 0.12$ & $14.60 \pm 0.56$ \\
\hline $24.541+0.312$ & 107.8 & 7.0 & 9.5 & 1.5 & 4.6 & - & - & - & - \\
\hline $24.635-0.323$ & 42.7 & 3.7 & 13.1 & 4.7 & 7.6 & $>6.7$ & $14.61 \pm 0.38$ & $6.39 \pm 0.12$ & $14.53 \pm 0.23$ \\
\hline $25.410+0.105$ & 96.0 & - & 9.5 & 3.4 & 7.0 & $6.42 \pm 0.11$ & $14.40 \pm 0.08$ & $6.22 \pm 0.07$ & $14.53 \pm 0.20$ \\
\hline $26.598-0.024$ & 23.3 & 1.8 & 13.4 & 1.8 & 32.6 & $>6.9$ & $14.54 \pm 0.42$ & $>6.5$ & $14.86 \pm 0.28$ \\
\hline $27.221+0.136$ & 112.6 & - & 8.0 & - & 9.4 & - & - & - & - \\
\hline $28.817+0.365$ & 87.0 & 5.5 & 9.4 & - & 5.3 & - & - & - & - \\
\hline $30.316+0.069$ & 45.3 & 2.8 & 12.2 & 2.2 & 3.3 & $>6.9$ & $14.77 \pm 0.18$ & $6.28 \pm 0.19$ & $14.59 \pm 0.09$ \\
\hline $30.398-0.297$ & 102.4 & 6.0 & 8.5 & 1.6 & 3.7 & $6.12 \pm 0.10$ & $14.83 \pm 0.08$ & - & - \\
\hline $31.056+0.361$ & 77.6 & - & 9.6 & - & 2.9 & - & - & - & - \\
\hline $31.156+0.045$ & 38.9 & 2.7 & 11.9 & 2.2 & 4.8 & $6.06 \pm 0.04$ & $14.11 \pm 0.06$ & $5.74 \pm 0.06$ & $14.64 \pm 0.13$ \\
\hline $31.585+0.080$ & 96.0 & 5.4 & 8.1 & - & 11.8 & - & - & - & - \\
\hline $32.966+0.041$ & 83.4 & 5.4 & 8.9 & 1.3 & 4.2 & - & - & $4.39 \pm 0.11$ & $15.73 \pm 0.16$ \\
\hline $33.648-0.224$ & 61.5 & - & 10.4 & - & 2.1 & - & - & - & - \\
\hline $33.980-0.019$ & 61.1 & 3.5 & 10.6 & 2.5 & 4.7 & - & - & $4.52 \pm 0.21$ & $15.76 \pm 0.13$ \\
\hline $34.753-0.092$ & 51.1 & 3.1 & 11.0 & - & 1.4 & - & - & - & - \\
\hline $35.791-0.175$ & 61.9 & 4.6 & 10.3 & 2.4 & 3.0 & - & - & - & - \\
\hline $36.115+0.552$ & 76.0 & 4.9 & 9.0 & 1.9 & 8.1 & - & - & $>6.8^{90}$ & $15.60 \pm 0.19^{90}$ \\
\hline $36.704+0.096$ & 59.8 & 4.6 & 10.4 & - & 0.9 & - & - & - & - \\
\hline $37.030-0.039$ & 80.1 & 5.0 & 8.3 & - & - & - & - & - & - \\
\hline $37.479-0.105$ & 59.1 & - & 9.5 & - & - & - & - & - & - \\
\hline $37.600+0.426$ & 90.0 & 6.5 & 7.5 & - & - & - & - & - & - \\
\hline $39.100+0.491$ & 23.1 & 1.0 & 14.7 & 2.0 & 2.9 & - & - & $6.58 \pm 0.08^{90}$ & $14.81 \pm 0.08^{90}$ \\
\hline
\end{tabular}

${ }^{90}$ Values for kinetic temperature $90 \mathrm{~K}$.

less plausible as a similar effect can be observed for $\mathrm{HCO}^{+}$and $\mathrm{H}^{13} \mathrm{CO}^{+}$lines.

\subsection{Gas density and temperature}

We used the escape-probability modelling code RADEX on$\operatorname{line}^{2}$ to estimate the density and temperature of the gas required for the observed line temperature ratios of $\mathrm{CS}$ and $\mathrm{C}^{34} \mathrm{~S}$. Because these parameters cannot be derived independently for diatomic molecules (Schilke et al. 2001) we calculate the models for 30, 60 and $90 \mathrm{~K}$ with gas number densities of $10^{4}-10^{7} \mathrm{~cm}^{-3}$, CS column densities of $10^{12}-10^{17} \mathrm{~cm}^{-2}$ and linewidth of $1 \mathrm{~km} \mathrm{~s}^{-1}$. We performed the calculations for the 16 sources for which all three CS lines were detected and we assumed that beam dilution is comparable for all these transitions. We used a $\chi^{2}$ minimization procedure to fit the models to the observed line ratios. The derived parameters are listed in Table 4 . We found equally reasonable fits for 10 sources using models at kinetic temperatures of both 30 and $60 \mathrm{~K}$. Five sources have good fits only for a single kinetic temperature. We could not find a satisfactory fit for the source $35.791-0.175$ as its $\operatorname{CS}(2-1)$ and $\operatorname{CS}(3-2)$ lines are strongly self-absorbed (Fig. A.1) and thus its line ratios are poorly constrained.

Using a temperature of $60 \mathrm{~K}$ the average logarithmic number density is $5.7 \pm 0.7$ and the average logarithmic column density of CS is $14.7 \pm 0.6$ for the sample. These values are consistent with 5.9 and 14.4, respectively, reported for a large sample of massive star formation sites selected by the

\footnotetext{
${ }^{2}$ http://www.strw.leidenuniv.nl/moldata/radex.php
}

presence of $\mathrm{H}_{2} \mathrm{O}$ masers (Plume et al. 1997). Our estimates are also in good agreement with those based on the ninepoint CS maps of high-mass protostellar candidates (Beuther et al. 2002a; Ossenkopf et al. 2001) and calculated with more sophisticated models. Taking the CS fractional abundance as $\sim 8 \times$ $10^{-9}$ (Beuther et al. 2002a) our estimate of the CS column density implies a mean $N\left(\mathrm{H}_{2}\right)$ of $6.3 \times 10^{22} \mathrm{~cm}^{-2}$ which is in very good agreement with the estimates based on $\mathrm{CO}$ and $\mathrm{HCO}^{+}$data (Sect. 5.1).

Our $\mathrm{C}^{34} \mathrm{~S}$ data are less useful to estimate the gas density and temperature because the line ratios are poorly constrained for most of the targets. $26.598-0.024$ is the only source for which we are able to determine $\mathrm{C}^{34} \mathrm{~S}$ line ratios but the results are inconsistent with those obtained from the CS data. This indicates that the escape probability model provides only a crude estimate to the physical parameters and the assumption of homogeneous parameters across the cloud is not fulfilled (Ossenkopf et al. 2001).

\section{Discussion}

\subsection{Kinematics}

The present survey reveals new information regarding the kinematics of molecular gas surrounding massive forming stars. In the following we attempt to answer the question of whether the 6.7 GHz methanol maser and the thermal molecular lines arise from similar or different kinematic regimes.

The velocity ranges of $6.7 \mathrm{GHz}$ methanol masers, ${ }^{13} \mathrm{CO}$ and $\mathrm{HCO}^{+}$line wings are plotted in Fig. 3. This plot clearly shows that the systemic velocity derived in this study (Table 4) is 


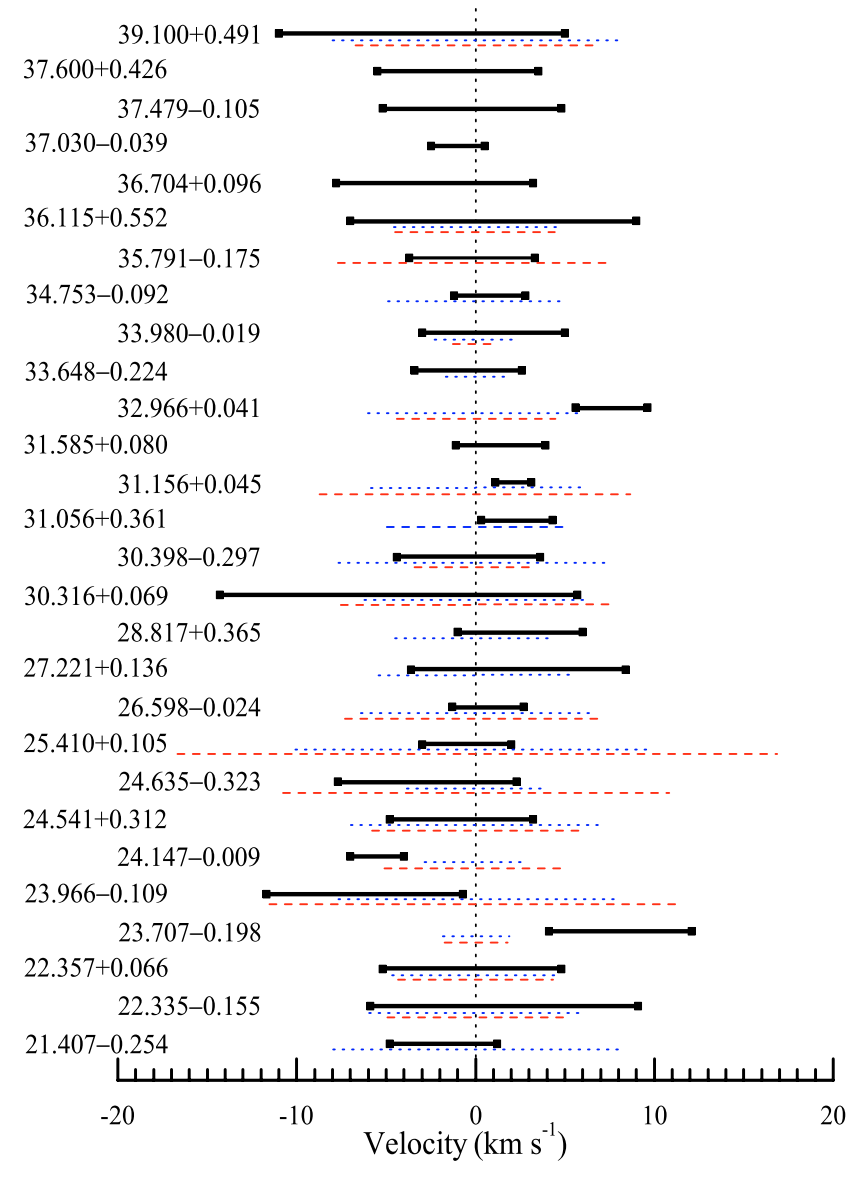

Fig. 3. Comparison between the velocity ranges of $6.7 \mathrm{GHz}$ methanol maser (thick bars) (Szymczak et al. 2002) and ${ }^{13} \mathrm{CO}$ (dotted bars) and $\mathrm{HCO}^{+}$(dashed bars) line wings. The dotted vertical line marks the systemic velocity.

in good agreement with the methanol maser central velocities, $V_{\mathrm{m}}$, derived from Szymczak et al. (2002). We note that in many sources $V_{\mathrm{m}}$ does not coincide with the peak maser velocity $V_{\mathrm{p}}$. The average value of $V_{\mathrm{m}}-V_{\text {sys }}$ is $0.04 \pm 0.60 \mathrm{~km} \mathrm{~s}^{-1}$. The difference is less than $3 \mathrm{~km} \mathrm{~s}^{-1}$ for 23 sources $(82 \%) . V_{\mathrm{m}}$ is offset by $>4$ and $\leq 8.1 \mathrm{~km} \mathrm{~s}^{-1}$ with respect to $V_{\text {sys }}$ in 5 sources $(18 \%)$, $23.707-0.198,23.966-0.109,24.147-0.009,30.316+0.069$ and 32.966+0.041 (Figs. 3 and A.1). This does not necessarily imply that the different species arise from separate regions along the same line of sight. Two of the sources, 24.147-0.009 and $32.966+0.041$, have ranges of maser emission $\Delta V_{\mathrm{m}} \leq$ $4 \mathrm{~km} \mathrm{~s}^{-1}$ which is a factor of two narrower than the mean value of $8.3 \pm 0.9 \mathrm{~km} \mathrm{~s}^{-1}$ for the sample but this could be simply an effect of inhomogeneous conditions in molecular clumps; the maser emission is sustained in one or a few clumps of sizes a few $\times 10^{15} \mathrm{~cm}$ (Minier et al. 2000). The effect of clumping is clearly seen even in regular structures (Bartkiewicz et al. 2005). The other three sources exhibit maser emission at velocities which differ from the systemic velocity by less than $4 \mathrm{~km} \mathrm{~s}^{-1}$. In source $30.316+0.069$ the maser spectrum is double (Szymczak et al.2000) and one of the peaks near $49 \mathrm{~km} \mathrm{~s}^{-1}$ is close to the systemic velocity of $45.3 \mathrm{~km} \mathrm{~s}^{-1}$, so that the maser emission related to the thermal molecular lines has a width of about $6 \mathrm{~km} \mathrm{~s}^{-1}$. We conclude, $V_{\mathrm{m}}$ is a reliable estimator of the systemic velocity, with an accuracy better than $3 \mathrm{~km} \mathrm{~s}^{-1}$, for most of the sources in our sample.

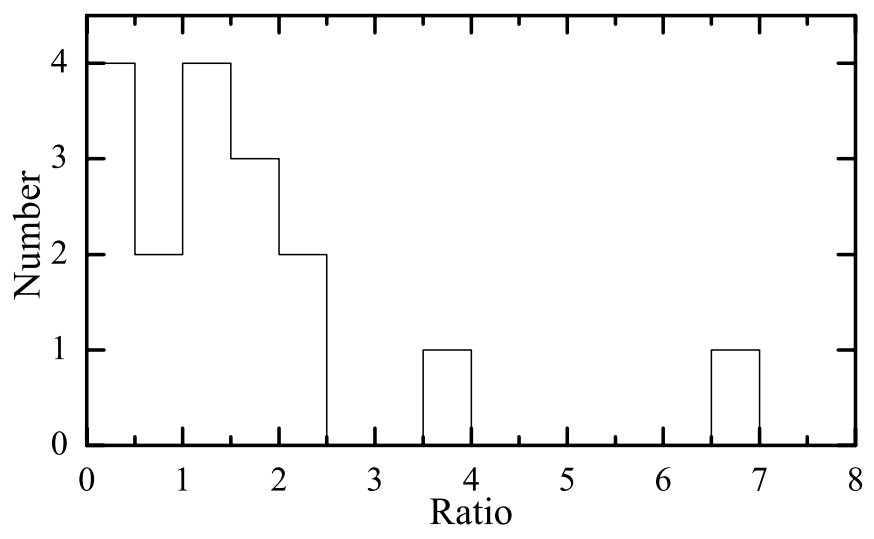

Fig. 4. Histogram of the ratio of methanol maser velocity spread to $\mathrm{HCO}^{+}$line wings spread.

The overlap between the velocity ranges of the methanol masers and the ${ }^{13} \mathrm{CO} / \mathrm{HCO}^{+}$line wings is remarkable. Figure 4 shows a histogram of the ratio of methanol maser velocity spread, $\Delta V_{\mathrm{m}}$, to $\mathrm{HCO}^{+}$line wings spread. This ratio ranges from $0.2-6.7$ and the median value is 1.3. Similar trends are observed in the ratio of $\Delta V_{\mathrm{m}}$ to ${ }^{13} \mathrm{CO}$ line wings spread. In 12 out of 23 sources where we detected ${ }^{13} \mathrm{CO} / \mathrm{HCO}^{+}$wings, $\Delta V_{\mathrm{m}}$ falls entirely within the wing velocity ranges and in 9 sources there is an overshoot of $\leq 4 \mathrm{~km} \mathrm{~s}^{-1}$. The ${ }^{13} \mathrm{CO} / \mathrm{HCO}^{+}$line wings appear to provide a good indication of the presence of outflow and their widths can serve as an approximate measure of outflow velocities. The present observations used beamwidths of $11^{\prime \prime}$ and $27^{\prime \prime}$ for ${ }^{13} \mathrm{CO}$ and $\mathrm{HCO}^{+}$lines, respectively, which sample a small fraction of the molecular cloud, centered on the methanol maser position.

The outflow velocity can be reliably estimated from these data only for the fortunate case when the axis of outflow lies along the line of sight. One source in our sample, 25.410+0.105, has been mapped in the ${ }^{12} \mathrm{CO}(2-1)$ line by Beuther et al. (2002b) who measured a wing velocity range of $14 \mathrm{~km} \mathrm{~s}^{-1}$, which is comparable with our estimate. In this object the maser emission, with velocity width of $5 \mathrm{~km} \mathrm{~s}^{-1}$, is closely centered on the systemic velocity. The velocity ranges of the ${ }^{13} \mathrm{CO}$ and $\mathrm{HCO}^{+}$wings are 11 and $18 \mathrm{~km} \mathrm{~s}^{-1}$, respectively. This indicates that the maser emission traces a small portion of the kinematic regime of the ${ }^{13} \mathrm{CO}$ and $\mathrm{HCO}^{+}$lines or it is completely unrelated. Figure 3 indicates that sources $21.407-0.254,26.598-0.024,31.156+0.045$ and $35.791-0.175$ share similar properties with $25.410+0.105$. VLBI observations of 35.791-0.175 (Bartkiewicz et al. 2004) support the above interpretation. In this object the $6.7 \mathrm{GHz}$ methanol maser emission appears to come from part of a circumstellar disc.

Our sample contains 4 objects (23.707-0.198, $24.147-0.009, \quad 32.966+0.041,36.115+0.552)$ for which the velocity range of the maser emission is very similar to or slightly overshoots that of the ${ }^{13} \mathrm{CO} / \mathrm{HCO}^{+}$line wings. If we assume that the width of ${ }^{13} \mathrm{CO}$ and $\mathrm{HCO}^{+}$line wings is a measure of the outflow velocity, in these objects the $6.7 \mathrm{GHz}$ methanol masers arise in outflows. This scenario appears to be supported by VLBI observations of 36.115+0.552 (Bartkiewicz et al. 2004); the maser emission comes from two well separated regions which probably represent a bipolar outflow. In this case the methanol maser traces the same or a very similar kinematic regime as that of the ${ }^{13} \mathrm{CO}$ and $\mathrm{HCO}^{+}$lines. 
Sources 22.355-0.155 and 27.221+0.136 appear to possess complex kinematics in the regions where the methanol masers operate. A close inspection of their $6.7 \mathrm{GHz}$ spectra (Szymczak et al.2002) suggests that some spectral features arise from the inner parts of the molecular cloud whilst other features form in outflows. VLBI studies of maser emission and detailed measurements of the kinematic properties of the molecular emission are needed to verify this suggestion.

\subsection{Implications for the evolutionary status}

One of the important findings of our observations is the detection of a considerable number of sources with line wings. We identified residual line wings in 18 out of 28 sources when a Gaussian profile was used to fit the $\mathrm{CO}, \mathrm{HCO}^{+}$and $\mathrm{CS}$ molecular lines. The line wings appear to be the best indicators of outflow motions in most cases. The presence of line wings in about $64 \%$ of sources in the sample suggests a close association of the methanol masers with the evolutionary phase when outflows occur. This result is consistent with that reported by Zhang et al. (2005). They mapped the $\operatorname{CO}(2-1)$ line in a sample of $69 \mathrm{lu}-$ minous IRAS point sources and found that about $60 \%$ of them were associated with outflows. However, with the present data we cannot resolve whether the methanol maser sites and the outflows have a common origin. Because of clustering in high mass star formation (e.g. Beuther et al.2002a) it is possible that some masers in the sample are not actually associated with outflowing sources.

Codella et al. (2004) proposed an evolutionary sequence for UCHII regions in which the earliest phase is marked by maser emission and molecular outflows not yet large enough to be detected with single-dish observations. The present data suggest that our sources are slightly more evolved because several of them show evidence of outflows. Their age therefore seems to be less than a few $10^{4}$ yr (Codella et al. 2004) which is consistent with a statistical estimate of $3-5 \times 10^{4} \mathrm{yr}$ for the methanol maser lifetime (van der Walt 2005).

\subsection{Constraints on maser models}

The present study allows us to refine the range of physical conditions required to produce strong methanol masers at $6.7 \mathrm{GHz}$. Theoretical modelling by Cragg et al. (2002) demonstrated that a maser line of $1 \mathrm{~km} \mathrm{~s}^{-1}$ width attains a peak brightness temperature of $\sim 10^{11} \mathrm{~K}$ for a dust temperature $>100 \mathrm{~K}$ and a methanol column density $>5 \times 10^{15} \mathrm{~cm}^{-2}$. They found that methanol masers can be produced under a wide range of the physical conditions. In fact, for a methanol fractional abundance from $3 \times 10^{-8}$ to $10^{-5}$, masing is predicted for the gas density range $10^{5}-2 \times 10^{8} \mathrm{~cm}^{-3}$ and the methanol column density range $5 \times 10^{15}-2 \times 10^{18} \mathrm{~cm}^{-2}$ (Cragg et al. 2002). The gas density inferred from our observations is between $10^{5}$ and $10^{7} \mathrm{~cm}^{-3}$; higher values $\left(>10^{7} \mathrm{~cm}^{-3}\right)$ are less probable. The hydrogen column density from $10^{22}$ to $2 \times 10^{23} \mathrm{~cm}^{-2}$, inferred here, translates well into the above range of methanol column densities for methanol fractional abundances of $5 \times 10^{-7}-10^{-5}$. This suggests that $6.7 \mathrm{GHz}$ maser emission is less probable in environments with a lower methanol fractional abundance of the order of $10^{-8}$. We conclude that our study well refines a range of the input parameters of Cragg et al.'s maser model. Specifically, a high methanol fractional abundance of $>5 \times 10^{-7}$ is required whilst a gas density $<10^{7} \mathrm{~cm}^{-3}$ is sufficient for the production of methanol masers.

\section{Conclusions}

We have observed 10 transitions of $\mathrm{HCO}^{+}, \mathrm{CO}$ and $\mathrm{CS}$ isotopomers at millimetre wavelengths in order to characterize the physical conditions in a sample of 28 MYSOs identified by the presence of methanol masers. No other preconditions were involved in the sample selection. The observations were centered at maser positions known with a sub-arcsecond accuracy. The main conclusions of the paper are summarized as follows:

1. The systemic velocity determined from the optically thin lines $\mathrm{C}^{18} \mathrm{O}(2-1), \mathrm{H}^{13} \mathrm{CO}^{+}(1-0), \mathrm{C}^{34}(2-1)$ and $\mathrm{C}^{34}(3-2)$ agrees within $\pm 3 \mathrm{~km} \mathrm{~s}^{-1}$ with the central velocity of the methanol maser emission for almost all the sources.

2. 18 out of 28 sources show residual line wings at least in one line when a Gaussian function was used to fit the $\mathrm{CO}, \mathrm{HCO}^{+}$ and CS lines. Detection of the line wing emission suggests the presence of molecular outflows in these sources. Their occurrence needs to be confirmed by mapping observations.

3. Comparison between the kinematics of the methanol masers and of the thermal molecular lines reveals that they trace a wide range of molecular cloud conditions. In some objects the maser emission occurs in a narrow velocity range centered at the systemic velocity, which may indicate that the innermost parts of a molecular cloud or a circumstellar disc is the site of maser emission. In other objects the velocities of maser features are very similar to, or slightly overshoot, the velocity ranges of the thermal molecular line wings, suggesting that the masers arise in outflows. There are also objects where the maser emission reveals more complex kinematics.

4. The column density of $\mathrm{H}_{2}$ derived from the $\mathrm{CO}$ and $\mathrm{HCO}^{+}$lines are between $10^{22}$ and $2 \times 10^{23} \mathrm{~cm}^{-2}$. We use our measurements of the intensity ratios of the CS lines to infer that methanol masers arise from regions with a gas density of $10^{5}-10^{7} \mathrm{~cm}^{-3}$, a kinetic temperature of $30-100 \mathrm{~K}$ and a methanol fractional abundance of $5 \times 10^{-7}-10^{-5}$. This represents a significant refinement to the input parameters of methanol maser models.

Acknowledgements. We like to thank the staff of the IRAM $30 \mathrm{~m}$ telescope for help with the observations and the unknown referee for helpful comments. This work has been supported by the Polish MNiI grant 1P03D02729.

\section{References}

Bartkiewicz, A., Szymczak, M., \& van Langevelde, H. J. 2004, in Proceedings of the 7th European VLBI Network Symposium, 187 [arXiv: astro-ph/0412002]

Bartkiewicz, A., Szymczak, M., \& van Langevelde, H. J. 2005, A\&A, 442, L61 Beuther, H., Kramer, C., Deiss, B., \& Stutzki, J. 2000, A\&A, 362, 1109 Beuther, H., Schilke, P., Menten, K. M., et al. 2002a, ApJ, 566, 945 Beuther, H., Schilke, P., Sridharan, T. K., et al. 2002b, ApJ, 383, 892 Brand, J., \& Blitz, L. 1993, A\&A, 275, 67

Brand, J., Cesaroni R., Palla, F., \& Molinari S. 2001, A\&A, 370, 230

Caswell, J. L., Vaile, R. A., Ellingsen, S. P., Whiteoak, J. B., \& Norris, R. P. 1995, MNRAS, 272, 96

Churchwell, E., Walmsley, C. M., \& Wood, D. O. S. 1992, A\&A, 253, 541

Codella, C., Lorenzani A., Gallego, A. T., Cesaroni, R., \& Moscadelli, L. 2004, A\&A, 417, 615

Codella, C., \& Moscadelli, L. 2000, A\&A, 362, 723

Cragg, D. M., Sobolev, A. M. \& Godfrey, P. D. 2002, MNRAS, 331, 521

Dartois, E., Schutte, W., Geballe, T. R., et al. 1999, A\&A, 342, L32

Girart, J. M., Estalella, R., Ho, P. T. P., \& Rudolph, A. L. 2000, ApJ, 539, 763

Frerking, M., Langer, W., \& Wilson, R. 1982, ApJ, 262, 590 
Fuller, G. A., Williams, S. J., \& Sridharan, T. K. 2005, A\&A, 442, 949 Lovas, F. J. 2002, NIST Recommended Rest Frequencies for Observed Interstellar Molecular Microwave Transitions - Revision: http://physics.nist.gov/PhysRefData/Micro/Html/ contents.html

Mardones, D., Myers, P. C., Tafalla, M., et al. 1997, ApJ, 489, 719

Menten, K. M. 1991, ApJ, 380, L75

Minier, V., Booth, R. S., \& Conway, J. E. 2000, A\&A, 362, 1093

Minier, V., Burton, M. G., Hill, T., et al. 2005, A\&A, 429, 945

Myers, P. C., Mardones, D., Tafalla, M., Williams, J. P., \& Wilner, D. J. 1996, ApJL, 465, 133

Narayanan, G., Walker, C. K., \& Buckley, H. D. 1998, ApJ, 496, 292

Niezurawska, A., Szymczak, M., Richards, A. M. S., \& Cohen, R. J. 2005, BaltA, 14,429

Norris, R. P., Byleveld, S. E., Diamond, P. J., et al. 1998, ApJ, 508, 275

Ossenkopf, V., Trojan, C., \& Stutzki J. 2001. A\&A, 378, 608

Plume, R., Jaffe, D.T., Evans, N.J.II, Martin-Pintado, J., \& Gomez-Gonzalez, J. 1997, ApJ, 476, 730
Purcell, C. R., Balasubramanyam, R., Burton, M. G., et al. 2006, MNRAS, 367, 553

Schilke, P., Pineau de Forets, G., Walmsley, C. M., \& Martin-Pintado, J. 2001, A\&A, 372, 291

Schutte, A. J., van der Walt, D. J., Gaylard, M. J., \& MacLeod, G. C. 1993 , MNRAS, 261,783

Szymczak, M., Hrynek, G., \& Kus, A. J. 2000, A\&AS, 143, 269

Szymczak, M., Kus, A. J., Hrynek, G., Kepa, A., \& Pazderski, E. 2002, A\&A, 392,277

Thompson, A. R., Moran, J. M., \& Swenson, J. R. 1991, Interferometry and synthesis in radio astronomy

van der Walt, J. 2005, MNRAS, 360, 153

van der Walt, D. J., Gaylard, M. J., \& MacLeod, G. C. 1995, A\&AS, 110, 81

Walsh, A. J., Hyland, A. R., Robinson, G., \& Burton, M. G. 1997, MNRAS, 291, 261

Walsh, A. J., Burton, M. G., Hyland, A. R., \& Robinson, G. 1998, MNRAS, 301, 640

Zhang, Q., Hunter, T. R., Brand, J., et al. 2005, ApJ, 625, 864 


\section{Online Material}


M. Szymczak et al.: Molecular line study of high-mass protostars, Online Material $p 2$

\section{Appendix A: Line parameters and spectra}

Table A.1. Results on line parameters. The parameters for tentative detections are italicized. ${ }^{i}$ possible interstellar origin of the red-shifted emission, ${ }^{s}$ smoothed, ${ }^{w}$ the $\Delta V$ in parentheses is the FWHM taken over the whole line for profiles with a dip which is $<0.5 T_{\text {peak }}$

\begin{tabular}{|c|c|c|c|c|c|c|c|c|}
\hline Source & Line & $\begin{array}{l}\mathrm{rms} \\
(\mathrm{K})\end{array}$ & $\begin{array}{l}V_{\mathrm{s}} \\
\left(\mathrm{km} \mathrm{s}^{-1}\right)\end{array}$ & $\begin{array}{l}V_{\mathrm{e}} \\
\left(\mathrm{km} \mathrm{s}^{-1}\right)\end{array}$ & $\begin{array}{l}T_{\mathrm{mb}} \\
(\mathrm{K})\end{array}$ & $\begin{array}{l}V_{\mathrm{p}} \\
\left(\mathrm{km} \mathrm{s}^{-1}\right)\end{array}$ & $\begin{array}{l}\Delta V \\
\left(\mathrm{~km} \mathrm{~s}^{-1}\right)\end{array}$ & $\begin{array}{l}\int T_{\mathrm{mb}} \mathrm{d} v \\
\left(\mathrm{~K} \mathrm{~km} \mathrm{~s}^{-1}\right)\end{array}$ \\
\hline \multirow[t]{8}{*}{$21.407-0.254$} & ${ }^{13} \mathrm{CO}(2-1)$ & 0.32 & 85.5 & 94.3 & 10.5 & 90.0 & 3.9 & 40.1 \\
\hline & $\mathrm{C}^{18} \mathrm{O}(2-1)$ & 0.26 & 87.5 & 93.5 & 4.4 & 90.6 & 2.7 & 12.8 \\
\hline & $\mathrm{HCO}^{+}(1-0)$ & 0.07 & & & & & & \\
\hline & $\mathrm{CS}(2-1)$ & 0.09 & 87.3 & 94.6 & 0.9 & 90.9 & 4.0 & 4.0 \\
\hline & $\operatorname{CS}(5-4)$ & 0.44 & 87.5 & 93.9 & 1.7 & 90.6 & 4.3 & 7.8 \\
\hline & $C^{34} S(2-1)^{s}$ & 0.08 & 88.8 & 92.8 & 0.2 & 90.8 & 3.3 & 0.8 \\
\hline & $\mathrm{C}^{34} \mathrm{~S}(3-2)^{s}$ & 0.09 & 87.7 & 92.5 & 0.3 & 90.1 & 4.1 & 1.3 \\
\hline & $C^{34} S(5-4)$ & 0.51 & & & & & & \\
\hline \multirow[t]{10}{*}{$22.335-0.155$} & ${ }^{13} \mathrm{CO}(2-1)$ & 0.37 & 26.1 & 36.3 & 15.0 & 31.4 & 4.4 & 64.6 \\
\hline & $\mathrm{C}^{18} \mathrm{O}(2-1)$ & 0.27 & 27.8 & 34.0 & 3.3 & 30.9 & 3.1 & 10.9 \\
\hline & $\mathrm{HCO}^{+}(1-0)$ & 0.08 & 24.9 & 35.8 & 1.4 & 32.7 & $2.6\left(8.0^{w}\right)$ & 6.9 \\
\hline & $\mathrm{H}^{13} \mathrm{CO}^{+}(1-0)$ & 0.07 & 28.1 & 33.4 & 0.6 & 30.6 & 2.8 & 1.7 \\
\hline & $\mathrm{CS}(2-1)$ & 0.08 & 26.0 & 35.8 & 1.9 & 31.6 & 4.6 & 8.8 \\
\hline & $\mathrm{CS}(3-2)$ & 0.17 & 26.7 & 35.8 & 2.0 & 31.0 & 4.5 & 9.6 \\
\hline & $\operatorname{CS}(5-4)$ & 0.45 & 28.7 & 33.0 & 1.6 & 30.8 & 3.2 & 5.6 \\
\hline & $\mathrm{C}^{34} \mathrm{~S}(2-1)^{s}$ & 0.08 & 28.7 & 33.1 & 0.3 & 30.9 & 3.2 & 1.0 \\
\hline & $C^{34} S(3-2)^{s}$ & 0.09 & 29.7 & 32.5 & 0.3 & 31.1 & 2.2 & 0.6 \\
\hline & $C^{34} S(5-4)$ & 0.48 & & & & & & \\
\hline \multirow[t]{10}{*}{$22.357+0.066$} & ${ }^{13} \mathrm{CO}(2-1)$ & 0.24 & 78.6 & 88.0 & 21.4 & 84.2 & 3.6 & 86.1 \\
\hline & $\mathrm{C}^{18} \mathrm{O}(2-1)$ & 0.22 & 80.7 & 86.8 & 13.4 & 83.9 & 2.5 & 35.0 \\
\hline & $\mathrm{HCO}^{+}(1-0)$ & 0.06 & 79.5 & 89.5 & 3.4 & 84.5 & 4.0 & 13.7 \\
\hline & $\mathrm{H}^{13} \mathrm{CO}^{+}(1-0)$ & 0.05 & 82.0 & 86.4 & 0.9 & 84.2 & 2.0 & 2.0 \\
\hline & $\mathrm{CS}(2-1)$ & 0.09 & 80.5 & 87.9 & 4.1 & 84.3 & 3.2 & 13.7 \\
\hline & $\mathrm{CS}(3-2)$ & 0.12 & 80.2 & 87.9 & 3.7 & 84.1 & 3.4 & 13.5 \\
\hline & $\operatorname{CS}(5-4)$ & 0.27 & 81.7 & 86.7 & 2.1 & 84.2 & 2.9 & 6.6 \\
\hline & $C^{34} S(2-1)$ & 0.09 & 82.2 & 86.5 & 0.9 & 84.2 & 2.2 & 2.2 \\
\hline & $C^{34} S(3-2)$ & 0.10 & 82.2 & 86.5 & 0.7 & 84.1 & 2.3 & 1.8 \\
\hline & $C^{34} S(5-4)$ & 0.33 & & & & & & \\
\hline \multirow[t]{10}{*}{$23.707-0.198$} & ${ }^{13} \mathrm{CO}(2-1)$ & 0.27 & 63.4 & 74.6 & 18.5 & 68.7 & 4.7 & 98.0 \\
\hline & $\mathrm{C}^{18} \mathrm{O}(2-1)$ & 0.24 & 64.8 & 73.4 & 7.4 & 68.7 & 4.0 & 34.7 \\
\hline & $\mathrm{HCO}^{+}(1-0)$ & 0.08 & 64.4 & 73.5 & 1.6 & 69.4 & 4.5 & 6.4 \\
\hline & $\mathrm{H}^{13} \mathrm{CO}^{+}(1-0)$ & 0.05 & 65.5 & 73.3 & 0.7 & 69.4 & 3.7 & 2.8 \\
\hline & $\mathrm{CS}(2-1)$ & 0.08 & 64.1 & 74.2 & 3.2 & 68.1 & 3.7 & 12.2 \\
\hline & $\mathrm{CS}(3-2)$ & 0.15 & 63.6 & 74.8 & 3.9 & 68.2 & 4.0 & 16.9 \\
\hline & $\operatorname{CS}(5-4)$ & 0.31 & 66.1 & 72.8 & 2.0 & 69.5 & 4.0 & 8.2 \\
\hline & $C^{34} S(2-1)$ & 0.09 & 66.5 & 71.2 & 0.7 & 68.9 & 2.6 & 1.8 \\
\hline & $C^{34} S(3-2)$ & 0.10 & 66.7 & 71.5 & 0.7 & 69.1 & 2.9 & 2.0 \\
\hline & $C^{34} S(5-4)$ & 0.42 & & & & & & \\
\hline \multirow[t]{10}{*}{$23.966-0.109$} & ${ }^{13} \mathrm{CO}(2-1)$ & 0.23 & 67.7 & 79.6 & 7.7 & 72.7 & $2.0\left(7.8^{w}\right)$ & 54.0 \\
\hline & $\mathrm{C}^{18} \mathrm{O}(2-1)$ & 0.23 & 67.6 & 77.5 & 6.3 & 72.3 & 4.3 & 28.1 \\
\hline & $\mathrm{HCO}^{+}(1-0)$ & 0.06 & 59.2 & 82.7 & 1.7 & 77.3 & $2.8\left(15.1^{w}\right)$ & 13.4 \\
\hline & $\mathrm{H}^{13} \mathrm{CO}^{+}(1-0)$ & 0.05 & 68.1 & 78.5 & 0.9 & 72.3 & 4.6 & 4.4 \\
\hline & $\mathrm{CS}(2-1)$ & 0.07 & 56.4 & 83.8 & 1.4 & 76.8 & 16.2 & 19.1 \\
\hline & $\operatorname{CS}(3-2)$ & 0.15 & 57.9 & 84.6 & 1.9 & 71.3 & $7.6\left(14.4^{w}\right)$ & 23.3 \\
\hline & $\mathrm{CS}(5-4)$ & 0.36 & 65.7 & 78.3 & 2.8 & 72.1 & 7.2 & 22.0 \\
\hline & $C^{34} S(2-1)$ & 0.10 & 68.0 & 77.4 & 0.5 & 72.7 & 5.8 & 3.4 \\
\hline & $C^{34} S(3-2)$ & 0.10 & 67.9 & 77.4 & 0.7 & 72.5 & 5.3 & 3.8 \\
\hline & $C^{34} S(5-4)$ & 0.45 & & & & & & \\
\hline \multirow[t]{10}{*}{$24.147-0.009$} & ${ }^{13} \mathrm{CO}(2-1)$ & 0.24 & 19.0 & 27.8 & 8.0 & 22.6 & 3.9 & 33.3 \\
\hline & $\mathrm{C}^{18} \mathrm{O}(2-1)$ & 0.24 & 20.6 & 25.5 & 3.1 & 23.1 & 2.5 & 8.3 \\
\hline & $\mathrm{HCO}^{+}(1-0)$ & 0.06 & 16.7 & 29.3 & 1.3 & 24.8 & 6.0 & 7.9 \\
\hline & $\mathrm{H}^{13} \mathrm{CO}^{+}(1-0)$ & 0.05 & 21.1 & 25.3 & 0.5 & 23.2 & 2.3 & 1.2 \\
\hline & $\mathrm{CS}(2-1)$ & 0.08 & 18.7 & 27.9 & 1.3 & 23.3 & 4.6 & 6.5 \\
\hline & $\operatorname{CS}(3-2)$ & 0.13 & 18.1 & 27.7 & 1.2 & 22.9 & 4.7 & 5.8 \\
\hline & $\operatorname{CS}(5-4)^{s}$ & 0.31 & 20.3 & 25.6 & 0.6 & 23.0 & 4.7 & 2.9 \\
\hline & $C^{34} S(2-1)$ & 0.06 & & & & & & \\
\hline & $C^{34} S(3-2)$ & 0.11 & & & & & & \\
\hline & $C^{34} S(5-4)$ & 0.47 & & & & & & \\
\hline \multirow[t]{3}{*}{$24.541+0.312$} & ${ }^{13} \mathrm{CO}(2-1)$ & 0.35 & 100. & 116. & 8.8 & 107.0 & $2.5\left(8.2^{w}\right)$ & 68.5 \\
\hline & $\mathrm{C}^{18} \mathrm{O}(2-1)$ & 0.26 & 101. & 114. & 5.2 & 107.8 & 2.8 & 20.6 \\
\hline & $\mathrm{HCO}^{+}(1-0)$ & 0.06 & 100. & 116. & 1.2 & 107.0 & $2.2\left(6.2^{w}\right)$ & 6.9 \\
\hline
\end{tabular}


M. Szymczak et al.: Molecular line study of high-mass protostars, Online Material $p 3$

Table A.1. continued.

\begin{tabular}{|c|c|c|c|c|c|c|c|c|}
\hline Source & Line & $\begin{array}{l}\mathrm{rms} \\
(\mathrm{K}) \\
\end{array}$ & $\begin{array}{l}V_{\mathrm{s}} \\
\left(\mathrm{km} \mathrm{s}^{-1}\right)\end{array}$ & $\begin{array}{l}V_{\mathrm{e}} \\
\left(\mathrm{km} \mathrm{s}^{-1}\right)\end{array}$ & $\begin{array}{l}T_{\mathrm{mb}} \\
(\mathrm{K})\end{array}$ & $\begin{array}{l}V_{\mathrm{p}} \\
\left(\mathrm{km} \mathrm{s}^{-1}\right)\end{array}$ & $\begin{array}{l}\Delta V \\
\left(\mathrm{~km} \mathrm{~s}^{-1}\right)\end{array}$ & 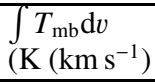 \\
\hline & $\mathrm{H}^{13} \mathrm{CO}^{+}(1-0)$ & 0.05 & 106. & 110. & 0.6 & 108.0 & 2.0 & 1.3 \\
\hline & $\mathrm{CS}(2-1)$ & 0.08 & 101. & 115. & 1.3 & 107.7 & $2.8\left(7.8^{w}\right)$ & 5.8 \\
\hline & $\mathrm{CS}(3-2)$ & 0.15 & 105. & 114. & 1.1 & 107.4 & $2.3\left(4.1^{w}\right)$ & 3.9 \\
\hline & $\mathrm{CS}(5-4)$ & 0.42 & & & & & & \\
\hline & $\mathrm{C}^{34} \mathrm{~S}(2-1)^{s}$ & 0.08 & 107. & 110. & 0.2 & 108.3 & 2.4 & 0.5 \\
\hline & $C^{34} S(3-2)$ & 0.15 & & & & & & \\
\hline & $C^{34} S(5-4)$ & 0.48 & & & & & & \\
\hline \multirow{10}{*}{$24.635-0.323$} & ${ }^{13} \mathrm{CO}(2-1)$ & 0.24 & 34.2 & 49.0 & 15.5 & 42.0 & 3.3 & 56.8 \\
\hline & $\mathrm{C}^{18} \mathrm{O}(2-1)$ & 0.26 & 40.0 & 46.2 & 7.6 & 42.3 & 2.4 & 20.1 \\
\hline & $\mathrm{HCO}^{+}(1-0)$ & 0.07 & 33.8 & 54.6 & 1.6 & 41.6 & 4.5 & 8.0 \\
\hline & $\mathrm{H}^{13} \mathrm{CO}^{+}(1-0)$ & 0.06 & 40.7 & 45.0 & 2.0 & 42.8 & 1.8 & 3.8 \\
\hline & $\mathrm{CS}(2-1)$ & 0.09 & 35.4 & 48.7 & 3.1 & 42.3 & 4.1 & 14.8 \\
\hline & $\mathrm{CS}(3-2)$ & 0.20 & 35.4 & 46.4 & 4.0 & 42.6 & 3.5 & 16.4 \\
\hline & $\operatorname{CS}(5-4)$ & 0.40 & 40.0 & 45.2 & 4.1 & 42.5 & 2.7 & 12.2 \\
\hline & $C^{34} S(2-1)$ & 0.10 & 39.9 & 45.7 & 0.6 & 42.7 & 3.5 & 2.3 \\
\hline & $C^{34} S(3-2)$ & 0.14 & 40.5 & 44.8 & 0.8 & 42.6 & 2.6 & 2.3 \\
\hline & $C^{34} S(5-4)$ & 0.48 & & & & & & \\
\hline \multirow{10}{*}{$25.410+0.105$} & ${ }^{13} \mathrm{CO}(2-1)$ & 0.27 & 85.9 & 104. & 14.7 & 96.3 & 5.6 & 83.4 \\
\hline & $\mathrm{C}^{18} \mathrm{O}(2-1)$ & 0.29 & 92.8 & 98.1 & 7.0 & 95.4 & 2.5 & 18.9 \\
\hline & $\mathrm{HCO}^{+}(1-0)$ & 0.11 & 81.0 & 111. & 4.4 & 97.3 & $4.5\left(11.2^{w}\right)$ & 37.7 \\
\hline & $\mathrm{H}^{13} \mathrm{CO}^{+}(1-0)$ & 0.06 & 91.0 & 101. & 1.5 & 95.7 & 1.8 & 4.4 \\
\hline & $\mathrm{CS}(2-1)$ & 0.08 & 79.8 & 107. & 2.6 & 96.5 & 8.9 & 23.1 \\
\hline & $\mathrm{CS}(3-2)$ & 0.16 & 85.6 & 107. & 3.0 & 96.3 & 8.4 & 25.1 \\
\hline & $\operatorname{CS}(5-4)$ & 0.41 & 94.0 & 101. & 2.6 & 96.2 & 5.7 & 15.5 \\
\hline & $C^{34} S(2-1)$ & 0.09 & 92.2 & 99.8 & 0.4 & 96.0 & 4.8 & 1.9 \\
\hline & $C^{34} S(3-2)$ & 0.11 & 92.3 & 101. & 0.4 & 96.2 & 5.6 & 2.3 \\
\hline & $C^{34} S(5-4)$ & 0.47 & & & & & & \\
\hline \multirow[t]{10}{*}{$26.598-0.024$} & ${ }^{13} \mathrm{CO}(2-1)$ & 0.29 & 17.7 & 34.1 & 34.2 & 22.0 & 3.5 & 149.5 \\
\hline & $\mathrm{C}^{18} \mathrm{O}(2-1)$ & 0.37 & 18.6 & 26.7 & 13.7 & 22.6 & 3.4 & 50.0 \\
\hline & $\mathrm{HCO}^{+}(1-0)$ & 0.06 & 18.3 & 35.2 & 1.5 & 20.5 & 3.0 & 6.8 \\
\hline & $\mathrm{H}^{13} \mathrm{CO}^{+}(1-0)$ & 0.05 & 20.0 & 25.5 & 0.5 & 22.7 & 3.0 & 1.7 \\
\hline & $\mathrm{CS}(2-1)$ & 0.09 & 18.8 & 29.5 & 3.6 & 22.8 & 3.2 & 14.3 \\
\hline & $\mathrm{CS}(3-2)$ & 0.14 & 17.5 & 29.9 & 5.3 & 22.7 & 2.8 & 21.8 \\
\hline & $\mathrm{CS}(5-4)$ & 0.43 & 19.8 & 28.5 & 8.6 & 23.6 & 4.5 & 40.0 \\
\hline & $C^{34} S(2-1)$ & 0.09 & 20.2 & 26.5 & 0.9 & 23.3 & 3.4 & 3.3 \\
\hline & $C^{34} S(3-2)$ & 0.13 & 19.8 & 27.6 & 1.8 & 23.6 & 3.8 & 7.2 \\
\hline & $C^{34} S(5-4)$ & 0.50 & 21.4 & 25.9 & 1.6 & 23.6 & 3.5 & 6.0 \\
\hline \multirow[t]{8}{*}{$27.221+0.136$} & ${ }^{13} \mathrm{CO}(2-1)$ & 0.48 & 108. & 117. & 22.2 & 112.6 & 3.5 & 82.9 \\
\hline & $\mathrm{C}^{18} \mathrm{O}(2-1)$ & 0.24 & 110. & 115. & 9.2 & 112.7 & 2.0 & 20.0 \\
\hline & $\mathrm{HCO}^{+}(1-0)$ & 0.07 & 109. & 116. & 3.3 & 112.7 & 2.8 & 10.7 \\
\hline & $\mathrm{CS}(2-1)$ & 0.10 & 108. & 117. & 2.1 & 112.7 & 2.9 & 6.6 \\
\hline & $\operatorname{CS}(5-4)$ & 0.57 & 109. & 116. & 3.1 & 112.3 & 4.7 & 15.7 \\
\hline & $C^{34} S(2-1)$ & 0.09 & 111. & 114. & 0.4 & 112.6 & 2.1 & 0.9 \\
\hline & $C^{34} S(3-2)$ & 0.11 & 110. & 115. & 0.7 & 112.4 & 2.6 & 2.0 \\
\hline & $C^{34} S(5-4)$ & 0.58 & & & & & & \\
\hline \multirow[t]{8}{*}{$28.817+0.365$} & ${ }^{13} \mathrm{CO}(2-1)$ & 0.28 & 77.8 & 92.9 & 16.9 & 85.8 & 3.5 & 74.1 \\
\hline & $\mathrm{C}^{18} \mathrm{O}(2-1)$ & 0.27 & 83.1 & 90.1 & 4.0 & 86.5 & 3.4 & 14.6 \\
\hline & $\mathrm{HCO}^{+}(1-0)$ & 0.13 & 77.3 & 93.3 & 4.3 & 85.1 & 3.6 & 20.7 \\
\hline & $\mathrm{CS}(2-1)$ & 0.09 & 78.4 & 94.4 & 2.4 & 85.7 & 6.0 & 14.9 \\
\hline & $\mathrm{CS}(5-4)$ & 0.32 & 81.5 & 93.4 & 4.8 & 87.4 & 6.1 & 31.3 \\
\hline & $C^{34} S(2-1)$ & 0.11 & 83.7 & 90.3 & 0.5 & 87.0 & 4.5 & 2.3 \\
\hline & $C^{34} S(3-2)$ & 0.12 & 83.1 & 91.2 & 1.0 & 87.0 & 4.5 & 4.7 \\
\hline & $C^{34} S(5-4)$ & 0.54 & & & & & & \\
\hline \multirow{10}{*}{$30.316+0.069$} & ${ }^{13} \mathrm{CO}(2-1)$ & 0.27 & 38.1 & 50.9 & 10.6 & 44.0 & 5.3 & 56.8 \\
\hline & $\mathrm{C}^{18} \mathrm{O}(2-1)$ & 0.26 & 41.6 & 47.9 & 3.4 & 44.8 & 3.1 & 11.5 \\
\hline & $\mathrm{HCO}^{+}(1-0)$ & 0.06 & 36.7 & 52.6 & 1.0 & 43.5 & $2.5\left(8.3^{w}\right)$ & 6.9 \\
\hline & $\mathrm{H}^{13} \mathrm{CO}^{+}(1-0)$ & 0.06 & 42.5 & 48.0 & 0.6 & 45.3 & 3.0 & 2.0 \\
\hline & $\mathrm{CS}(2-1)$ & 0.09 & 40.4 & 49.2 & 1.2 & 44.3 & 4.6 & 5.9 \\
\hline & $\mathrm{CS}(3-2)$ & 0.14 & 40.1 & 49.4 & 1.4 & 44.2 & 5.3 & 6.8 \\
\hline & $\mathrm{CS}(5-4)$ & 0.32 & 40.8 & 49.0 & 1.7 & 44.8 & 5.4 & 9.4 \\
\hline & $C^{34} S(2-1)^{s}$ & 0.09 & 43.3 & 47.5 & 0.2 & 45.3 & 3.0 & 0.6 \\
\hline & $C^{34} S(3-2)^{s}$ & 0.10 & 40.7 & 49.8 & 0.2 & 45.1 & 6.8 & 1.5 \\
\hline & $C^{34} S(5-4)$ & 0.47 & & & & & & \\
\hline \multirow[t]{2}{*}{$30.398-0.297$} & ${ }^{13} \mathrm{CO}(2-1)$ & 0.30 & 93.9 & 112. & 18.1 & 102.1 & 3.1 & 85.8 \\
\hline & $\mathrm{C}^{18} \mathrm{O}(2-1)$ & 0.29 & 97.8 & 104. & 4.3 & 101.8 & 2.1 & 11.7 \\
\hline
\end{tabular}


M. Szymczak et al.: Molecular line study of high-mass protostars, Online Material p 4

Table A.1. continued.

\begin{tabular}{|c|c|c|c|c|c|c|c|c|}
\hline Source & Line & $\begin{array}{l}\mathrm{rms} \\
(\mathrm{K})\end{array}$ & $\begin{array}{l}V_{\mathrm{s}} \\
\left(\mathrm{km} \mathrm{s}^{-1}\right)\end{array}$ & $\begin{array}{l}V_{\mathrm{e}} \\
\left(\mathrm{km} \mathrm{s}^{-1}\right)\end{array}$ & $\begin{array}{l}T_{\mathrm{mb}} \\
(\mathrm{K})\end{array}$ & $\begin{array}{l}V_{\mathrm{p}} \\
\left(\mathrm{km} \mathrm{s}^{-1}\right)\end{array}$ & $\begin{array}{l}\Delta V \\
\left(\mathrm{~km} \mathrm{~s}^{-1}\right)\end{array}$ & $\begin{array}{l}\int T_{\mathrm{mb}} \mathrm{d} v \\
\left(\mathrm{~K}\left(\mathrm{~km} \mathrm{~s}^{-1}\right)\right.\end{array}$ \\
\hline & $\mathrm{HCO}^{+}(1-0)$ & 0.08 & 94.2 & 107. & 3.4 & 102.6 & 2.3 & 12.5 \\
\hline & $\mathrm{H}^{13} \mathrm{CO}^{+}(1-0)$ & 0.06 & 101. & 104. & 0.7 & 102.6 & 1.8 & 1.3 \\
\hline & $\mathrm{CS}(2-1)$ & 0.09 & 94.5 & 112. & 2.2 & 102.3 & 2.1 & 9.0 \\
\hline & $\mathrm{CS}(3-2)$ & 0.18 & 99.0 & 105. & 2.1 & 102.2 & 3.5 & 7.6 \\
\hline & $\mathrm{CS}(5-4)$ & 0.33 & 99.9 & 105. & 1.8 & 102.3 & 3.0 & 5.8 \\
\hline & $\mathrm{C}^{34} \mathrm{~S}(2-1)^{s}$ & 0.08 & 98.4 & 106. & 0.2 & 102.1 & 4.8 & 1.1 \\
\hline & $\mathrm{C}^{34} \mathrm{~S}(3-2)^{s}$ & 0.10 & 101. & 103. & 0.5 & 102.4 & 1.4 & 0.7 \\
\hline & $C^{34} S(5-4)$ & 0.75 & & & & & & \\
\hline \multirow{8}{*}{$31.056+0.361$} & ${ }^{13} \mathrm{CO}(2-1)$ & 0.24 & 73.6 & 83.2 & 8.4 & 77.8 & 3.3 & 36.6 \\
\hline & $\mathrm{C}^{18} \mathrm{O}(2-1)$ & 0.32 & 75.8 & 79.5 & 5.2 & 77.6 & 1.8 & 9.8 \\
\hline & $\mathrm{HCO}^{+}(1-0)$ & 0.06 & 73.6 & 78.9 & 0.5 & 76.2 & 2.2 & 1.2 \\
\hline & $\mathrm{CS}(2-1)$ & 0.10 & 75.6 & 80.0 & 1.0 & 77.7 & 2.2 & 2.4 \\
\hline & $\operatorname{CS}(5-4)$ & 0.30 & & & & & & \\
\hline & $C^{34} S(2-1)$ & 0.10 & & & & & & \\
\hline & $C^{34} S(3-2)$ & 0.12 & & & & & & \\
\hline & $C^{34} S(5-4)$ & 0.85 & & & & & & \\
\hline \multirow[t]{10}{*}{$31.156+0.045$} & ${ }^{13} \mathrm{CO}(2-1)$ & 0.20 & 31.7 & 46.8 & 10.0 & 39.0 & 6.4 & 57.5 \\
\hline & $\mathrm{C}^{18} \mathrm{O}(2-1)$ & 0.35 & 34.5 & 42.4 & 3.5 & 39.1 & 4.5 & 15.2 \\
\hline & $\mathrm{HCO}^{+}(1-0)$ & 0.06 & 29.4 & 48.5 & 1.2 & 38.6 & 5.7 & 6.7 \\
\hline & $\mathrm{H}^{13} \mathrm{CO}^{+}(1-0)$ & 0.06 & 36.6 & 41.5 & 0.7 & 38.9 & 2.5 & 1.7 \\
\hline & $\mathrm{CS}(2-1)$ & 0.07 & 30.7 & 44.8 & 3.2 & 38.8 & 3.0 & 11.5 \\
\hline & $\mathrm{CS}(3-2)$ & 0.20 & 31.2 & 44.1 & 3.6 & 38.8 & 2.9 & 14.4 \\
\hline & $\mathrm{CS}(5-4)$ & 0.30 & 36.3 & 41.2 & 2.4 & 38.7 & 2.7 & 7.1 \\
\hline & $C^{34} S(2-1)$ & 0.09 & 36.8 & 41.0 & 0.5 & 38.9 & 2.6 & 1.4 \\
\hline & $C^{34} S(3-2)$ & 0.10 & 37.4 & 40.6 & 0.5 & 39.0 & 2.1 & 1.2 \\
\hline & $C^{34} S(5-4)$ & 0.65 & & & & & & \\
\hline \multirow[t]{8}{*}{$31.585+0.080$} & ${ }^{13} \mathrm{CO}(2-1)$ & 0.27 & 93.3 & 112. & 16.7 & 96.2 & 3.1 & 70.6 \\
\hline & $\mathrm{C}^{18} \mathrm{O}(2-1)$ & 0.32 & 92.7 & 99.7 & 7.6 & 96.1 & 3.6 & 31.8 \\
\hline & $\mathrm{HCO}^{+}(1-0)$ & 0.08 & 91.4 & 101. & 3.1 & 96.2 & 4.2 & 14.2 \\
\hline & $\mathrm{CS}(2-1)$ & 0.10 & 90. & 102. & 4.6 & 95.7 & 4.6 & 21.7 \\
\hline & $\mathrm{CS}(5-4)$ & 0.29 & & & & & & \\
\hline & $C^{34} S(2-1)$ & 0.10 & 92.6 & 99.6 & 1.3 & 96.1 & 3.5 & 5.0 \\
\hline & $C^{34} S(3-2)$ & 0.10 & 95.1 & 96.9 & 0.6 & 96.0 & 1.1 & 0.7 \\
\hline & $C^{34} S(5-4)$ & 0.64 & & & & & & \\
\hline \multirow[t]{10}{*}{$32.966+0.041$} & ${ }^{13} \mathrm{CO}(2-1)^{i}$ & 0.26 & 74.7 & 88.5 & 9.8 & 82.5 & 4.9 & 66.4 \\
\hline & $\mathrm{C}^{18} \mathrm{O}(2-1)$ & 0.22 & 78.8 & 86.3 & 5.5 & 83.1 & 2.3 & 13.4 \\
\hline & $\mathrm{HCO}^{+}(1-0)^{i}$ & 0.06 & 78.6 & 91.3 & 0.7 & 81.2 & 2.3 & 4.4 \\
\hline & $\mathrm{H}^{13} \mathrm{CO}^{+}(1-0)$ & 0.06 & 80.4 & 86.0 & 0.5 & 83.4 & 2.1 & 1.2 \\
\hline & $\mathrm{CS}(2-1)$ & 0.07 & 78.2 & 88.0 & 1.6 & 82.8 & 3.6 & 5.7 \\
\hline & $\mathrm{CS}(3-2)$ & 0.13 & 79.9 & 86.1 & 1.2 & 83.0 & 3.3 & 4.4 \\
\hline & $\mathrm{CS}(5-4)$ & 0.28 & 81.3 & 84.9 & 1.0 & 83.0 & 2.4 & 2.6 \\
\hline & $\mathrm{C}^{34} \mathrm{~S}(2-1)^{s}$ & 0.08 & 79.8 & 87.3 & 0.2 & 83.4 & 5.4 & 1.0 \\
\hline & $C^{34} S(3-2)$ & 0.10 & & & & & & \\
\hline & $C^{34} S(5-4)$ & 0.35 & & & & & & \\
\hline \multirow[t]{10}{*}{$33.648-0.224$} & ${ }^{13} \mathrm{CO}(2-1)$ & 0.26 & 58.8 & 64.6 & 14.7 & 61.7 & 2.4 & 37.4 \\
\hline & $\mathrm{C}^{18} \mathrm{O}(2-1)$ & 0.28 & 59.7 & 62.8 & 3.6 & 61.2 & 1.6 & 6.2 \\
\hline & $\mathrm{HCO}^{+}(1-0)$ & 0.06 & 57.3 & 66.1 & 0.9 & 62.2 & 4.1 & 3.9 \\
\hline & $\mathrm{H}^{13} \mathrm{CO}^{+}(1-0)$ & 0.05 & & & & & & \\
\hline & $\operatorname{CS}(2-1)$ & 0.08 & 59.4 & 63.7 & 1.0 & 61.6 & 2.2 & 2.3 \\
\hline & $\operatorname{CS}(3-2)^{s}$ & 0.16 & 59.9 & 62.9 & 0.7 & 61.4 & 1.7 & 1.2 \\
\hline & $\mathrm{CS}(5-4)$ & 0.24 & & & & & & \\
\hline & $\mathrm{C}^{34} \mathrm{~S}(2-1)^{s}$ & 0.08 & 58.8 & 63.3 & 0.2 & 61.1 & 3.5 & 0.6 \\
\hline & $C^{34} S(3-2)$ & 0.10 & & & & & & \\
\hline & $C^{34} S(5-4)$ & 0.52 & & & & & & \\
\hline \multirow[t]{10}{*}{$33.980-0.019$} & ${ }^{13} \mathrm{CO}(2-1)$ & 0.20 & 54.4 & 65.9 & 9.8 & 59.7 & 5.3 & 42.7 \\
\hline & $\mathrm{C}^{18} \mathrm{O}(2-1)$ & 0.38 & 57.8 & 64.3 & 4.3 & 61.0 & 3.5 & 15.9 \\
\hline & $\mathrm{HCO}^{+}(1-0)$ & 0.06 & 56.6 & 68.0 & 1.7 & 60.1 & 2.0 & 5.0 \\
\hline & $\mathrm{H}^{13} \mathrm{CO}^{+}(1-0)$ & 0.06 & 59.0 & 64.1 & 0.8 & 61.5 & 2.5 & 2.2 \\
\hline & $\operatorname{CS}(2-1)$ & 0.12 & 56.0 & 66.2 & 1.6 & 61.1 & 5.2 & 8.8 \\
\hline & $\mathrm{CS}(3-2)$ & 0.14 & 55.3 & 66.8 & 1.2 & 60.9 & 6.3 & 8.3 \\
\hline & $\mathrm{CS}(5-4)^{s}$ & 0.25 & 60.1 & 63.6 & 0.9 & 61.8 & 2.8 & 2.6 \\
\hline & $C^{34} S(2-1)$ & 0.11 & & & & & & \\
\hline & $C^{34} S(3-2)$ & 0.12 & & & & & & \\
\hline & $C^{34} S(5-4)$ & 0.80 & & & & & & \\
\hline $34.753-0.092$ & ${ }^{13} \mathrm{CO}(2-1)$ & 0.28 & 45.8 & 57.4 & 8.1 & 51.7 & 3.2 & 28.5 \\
\hline
\end{tabular}


M. Szymczak et al.: Molecular line study of high-mass protostars, Online Material p 5

Table A.1. continued.

\begin{tabular}{|c|c|c|c|c|c|c|c|c|}
\hline Source & Line & $\begin{array}{l}\mathrm{rms} \\
(\mathrm{K}) \\
\end{array}$ & $\begin{array}{l}V_{\mathrm{s}} \\
\left(\mathrm{km} \mathrm{s}^{-1}\right)\end{array}$ & $\begin{array}{l}V_{\mathrm{e}} \\
\left(\mathrm{km} \mathrm{s}^{-1}\right)\end{array}$ & $\begin{array}{l}T_{\mathrm{mb}} \\
(\mathrm{K}) \\
\end{array}$ & $\begin{array}{l}V_{\mathrm{p}} \\
\left(\mathrm{km} \mathrm{s}^{-1}\right)\end{array}$ & $\begin{array}{l}\Delta V \\
\left(\mathrm{~km} \mathrm{~s}^{-1}\right)\end{array}$ & $\begin{array}{l}\int T_{\mathrm{mb}} \mathrm{d} v \\
\left(\mathrm{~K}\left(\mathrm{~km} \mathrm{~s}^{-1}\right)\right.\end{array}$ \\
\hline & $\mathrm{C}^{18} \mathrm{O}(2-1)$ & 0.37 & 49.5 & 52.7 & 2.9 & 51.0 & 1.7 & 5.4 \\
\hline & $\mathrm{HCO}^{+}(1-0)$ & 0.07 & 46.6 & 54.8 & 1.6 & 51.1 & 1.4 & 4.5 \\
\hline & $\mathrm{CS}(2-1)$ & 0.11 & 48.7 & 53.6 & 1.7 & 51.2 & 2.4 & 4.3 \\
\hline & $\mathrm{CS}(5-4)$ & 0.38 & & & & & & \\
\hline & $\mathrm{C}^{34} \mathrm{~S}(2-1)^{s}$ & 0.08 & 50.0 & 53.2 & 0.2 & 51.6 & 2.4 & 0.5 \\
\hline & $C^{34} S(3-2)$ & 0.12 & & & & & & \\
\hline & $C^{34} S(5-4)$ & 0.90 & & & & & & \\
\hline \multirow[t]{10}{*}{$35.791-0.175$} & ${ }^{13} \mathrm{CO}(2-1)$ & 0.20 & 56.0 & 66.8 & 3.8 & 62.9 & 6.5 & 18.1 \\
\hline & $\mathrm{C}^{18} \mathrm{O}(2-1)$ & 0.66 & 57.9 & 63.9 & 3.2 & 60.9 & 3.9 & 13.3 \\
\hline & $\mathrm{HCO}^{+}(1-0)$ & 0.09 & 52.9 & 72.7 & 1.3 & 63.9 & 2.8 & 6.2 \\
\hline & $\mathrm{H}^{13} \mathrm{CO}^{+}(1-0)$ & 0.08 & 58.8 & 64.4 & 0.6 & 61.6 & 3.2 & 2.1 \\
\hline & $\operatorname{CS}(2-1)$ & 0.09 & 55.7 & 70.6 & 2.2 & 63.3 & $1.9\left(8.3^{w}\right)$ & 11.7 \\
\hline & $\operatorname{CS}(3-2)$ & 0.28 & 56.5 & 68.8 & 2.1 & 63.2 & $3.3\left(9.5^{w}\right)$ & 12.3 \\
\hline & $\mathrm{CS}(5-4)$ & 0.24 & 55.4 & 68.4 & 1.7 & 61.9 & 6.1 & 10.7 \\
\hline & $C^{34} S(2-1)$ & 0.09 & 58.4 & 64.9 & 0.4 & 61.7 & 4.4 & 2.1 \\
\hline & $C^{34} S(3-2)$ & 0.07 & 58.2 & 66.1 & 0.4 & 62.2 & 5.1 & 1.9 \\
\hline & $C^{34} S(5-4)$ & 0.61 & & & & & & \\
\hline \multirow[t]{10}{*}{$36.115+0.552$} & ${ }^{13} \mathrm{CO}(2-1)$ & 0.22 & 71.1 & 81.4 & 14.2 & 77.4 & 4.4 & 54.1 \\
\hline & $\mathrm{C}^{18} \mathrm{O}(2-1)$ & 0.63 & 73.7 & 78.5 & 8.1 & 76.1 & 2.4 & 20.8 \\
\hline & $\mathrm{HCO}^{+}(1-0)$ & 0.05 & 71.5 & 79.9 & 1.5 & 75.2 & $1.3\left(3.9^{w}\right)$ & 4.8 \\
\hline & $\mathrm{H}^{13} \mathrm{CO}^{+}(1-0)$ & 0.07 & 74.5 & 77.8 & 0.9 & 76.2 & 1.7 & 1.7 \\
\hline & $\mathrm{CS}(2-1)$ & 0.10 & 72.5 & 86.9 & 1.3 & 75.8 & $3.3^{i}$ & 4.6 \\
\hline & $\mathrm{CS}(3-2)$ & 0.20 & 73.2 & 78.7 & 1.8 & 76.0 & 3.2 & 6.1 \\
\hline & $\mathrm{CS}(5-4)$ & 0.31 & 73.7 & 78.3 & 4.2 & 76.0 & 2.4 & 10.7 \\
\hline & $C^{34} S(2-1)$ & 0.10 & 74.7 & 77.5 & 0.5 & 76.0 & 1.7 & 0.9 \\
\hline & $C^{34} S(3-2)$ & 0.10 & 74.4 & 77.9 & 1.0 & 76.1 & 1.9 & 1.9 \\
\hline & $C^{34} S(5-4)$ & 0.71 & & & & & & \\
\hline \multirow[t]{8}{*}{$36.704+0.096$} & ${ }^{13} \mathrm{CO}(2-1)$ & 0.28 & 56.5 & 63.9 & 9.0 & 59.5 & 2.6 & 27.5 \\
\hline & $\mathrm{C}^{18} \mathrm{O}(2-1)$ & 0.61 & 58.8 & 60.9 & 2.1 & 59.8 & 1.6 & 3.5 \\
\hline & $\mathrm{HCO}^{+}(1-0)$ & 0.07 & 53.6 & 64.6 & 2.4 & 59.7 & 3.0 & 8.7 \\
\hline & $\mathrm{CS}(2-1)$ & 0.14 & 57.9 & 61.9 & 1.2 & 59.8 & 2.2 & 2.7 \\
\hline & $\mathrm{CS}(3-2)$ & 0.13 & 57.7 & 61.8 & 0.6 & 59.7 & 2.9 & 1.8 \\
\hline & $C^{34} S(2-1)$ & 0.16 & & & & & & \\
\hline & $C^{34} S(3-2)$ & 0.13 & & & & & & \\
\hline & $C^{34} S(5-4)$ & 1.20 & & & & & & \\
\hline \multirow[t]{4}{*}{$37.030-0.039$} & ${ }^{13} \mathrm{CO}(2-1)$ & 0.27 & 71.7 & 84.5 & 12.2 & 79.9 & 3.7 & 54.8 \\
\hline & $\mathrm{HCO}^{+}(1-0)$ & 0.09 & 77.6 & 82.8 & 1.9 & 79.1 & $1.5\left(3.0^{w}\right)$ & 4.5 \\
\hline & $\mathrm{CS}(5-4)$ & 0.43 & 77.4 & 82.9 & 1.8 & 80.1 & 3.8 & 7.2 \\
\hline & $\mathrm{C}^{34} \mathrm{~S}(3-2)^{s}$ & 0.11 & 77.6 & 84.8 & 0.3 & 81.2 & 5.6 & 2.0 \\
\hline \multirow[t]{4}{*}{$37.479-0.105$} & ${ }^{13} \mathrm{CO}(2-1)$ & 0.40 & 54.0 & 64.6 & 28.0 & 58.7 & 3.5 & 102.0 \\
\hline & $\mathrm{HCO}^{+}(1-0)$ & 0.09 & 54.6 & 62.1 & 5.8 & 58.6 & 2.9 & 17.5 \\
\hline & $\mathrm{CS}(5-4)$ & 0.45 & 57.1 & 61.1 & 3.0 & 59.1 & 2.4 & 7.8 \\
\hline & $C^{34} S(3-2)$ & 0.17 & 56.8 & 61.3 & 0.8 & 59.1 & 2.5 & 2.0 \\
\hline \multirow[t]{4}{*}{$37.600+0.426$} & ${ }^{13} \mathrm{CO}(2-1)$ & 0.34 & 83.5 & 94.8 & 11.0 & 89.6 & 2.6 & 33.2 \\
\hline & $\mathrm{HCO}^{+}(1-0)$ & 0.08 & 84.2 & 95.3 & 5.5 & 90.0 & 2.9 & 17.1 \\
\hline & $\mathrm{CS}(5-4)$ & 0.48 & & & & & & \\
\hline & $C^{34} S(3-2)$ & 0.23 & & & & & & \\
\hline \multirow{10}{*}{$39.100+0.491$} & ${ }^{13} \mathrm{CO}(2-1)$ & 0.25 & 11.3 & 31.5 & 8.2 & 21.3 & 7.9 & 68.2 \\
\hline & $\mathrm{C}^{18} \mathrm{O}(2-1)$ & 0.55 & 20.5 & 25.1 & 3.6 & 22.8 & 2.8 & 10.8 \\
\hline & $\mathrm{HCO}^{+}(1-0)$ & 0.10 & 15.0 & 29.5 & 1.7 & 21.5 & $5.3\left(8.3^{w}\right)$ & 13.5 \\
\hline & $\mathrm{H}^{13} \mathrm{CO}^{+}(1-0)$ & 0.06 & 21.0 & 25.3 & 0.7 & 23.1 & 2.3 & 1.6 \\
\hline & $\mathrm{CS}(2-1)$ & 0.18 & 16.5 & 30.8 & 2.3 & 23.6 & 7.6 & 18.8 \\
\hline & $\mathrm{CS}(3-2)$ & 0.25 & 14.4 & 33.5 & 3.3 & 25.0 & 10.2 & 32.0 \\
\hline & $\mathrm{CS}(5-4)$ & 0.39 & 13.6 & 33.3 & 4.2 & 23.5 & 11.1 & 49.1 \\
\hline & $C^{34} S(2-1)^{s}$ & 0.13 & 21.4 & 24.5 & 0.5 & 23.0 & 2.4 & 1.3 \\
\hline & $C^{34} S(3-2)$ & 0.11 & 18.1 & 28.1 & 0.6 & 23.0 & 6.4 & 4.2 \\
\hline & $C^{34} S(5-4)$ & 0.51 & & & & & & \\
\hline
\end{tabular}


M. Szymczak et al.: Molecular line study of high-mass protostars, Online Material p 6

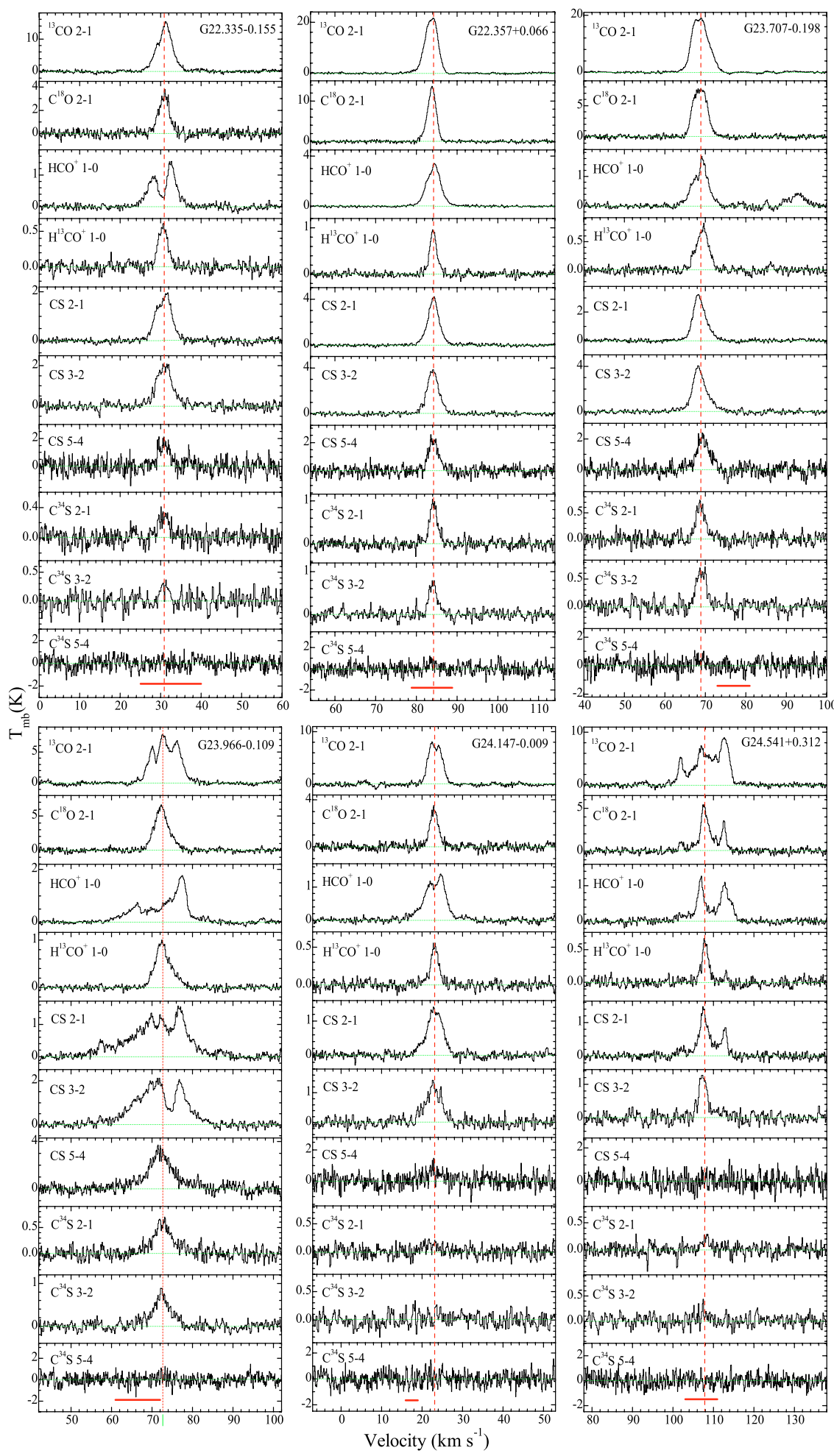

Fig. A.1. Spectra of sources. Source names, molecules and transitions are indicated. The main beam brightness temperature $\left(T_{\mathrm{mb}}\right)$ is plotted against velocity $\left(V_{\mathrm{LSR}}\right)$. The dashed vertical line shows the systemic velocity as inferred from a Gaussian fit of one of the optically thin transition (see text for details) for each target. The dotted horizontal lines show the $T_{\mathrm{mb}}=0 \mathrm{~K}$ level in each spectrum. The thick bottom bar indicates the velocity range of the $6.7 \mathrm{GHz}$ methanol maser emission (Szymczak et al. 2002) for each source. 
M. Szymczak et al.: Molecular line study of high-mass protostars, Online Material $p 7$

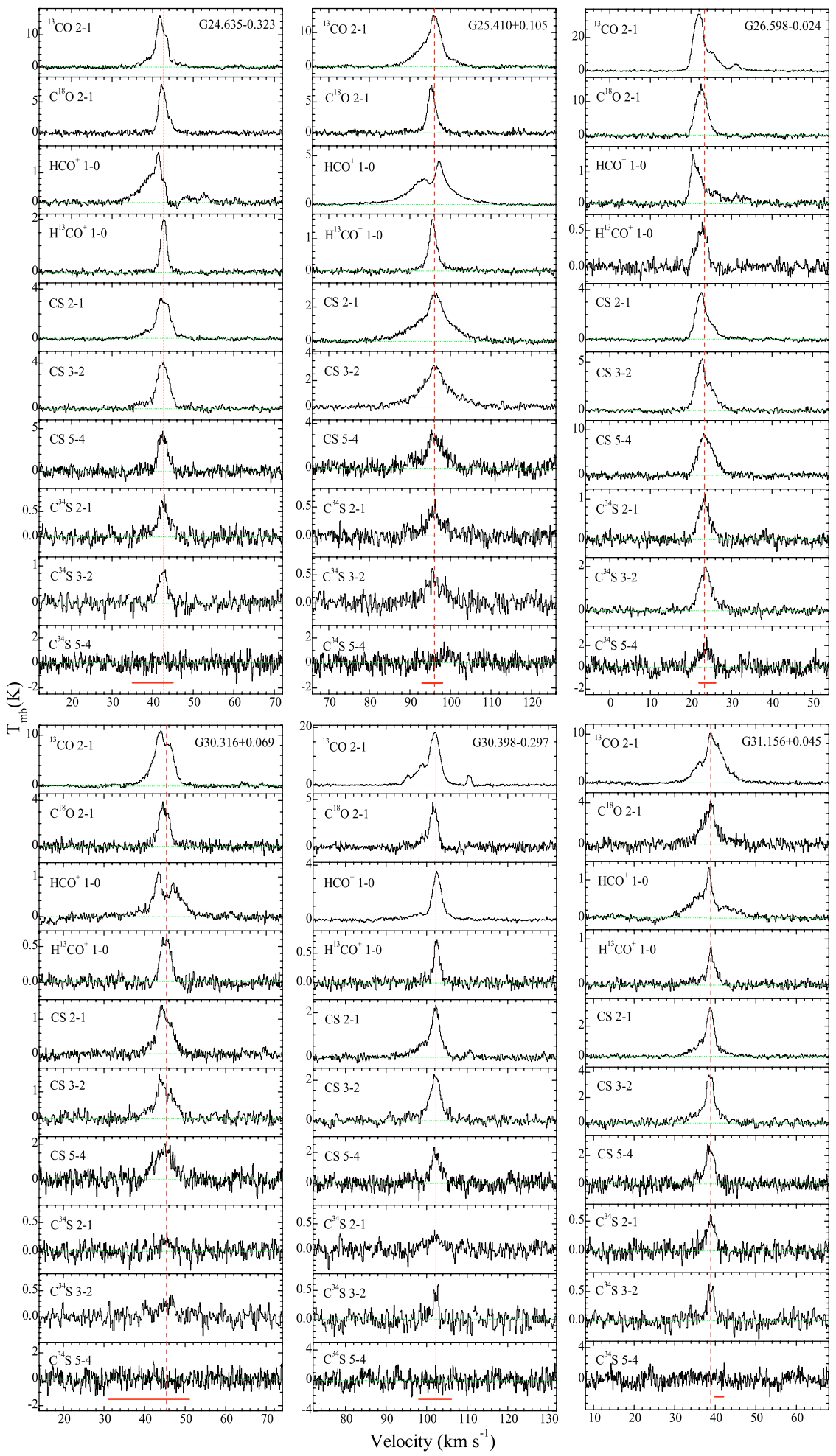

Fig. A.1. continued. 
M. Szymczak et al.: Molecular line study of high-mass protostars, Online Material p 8
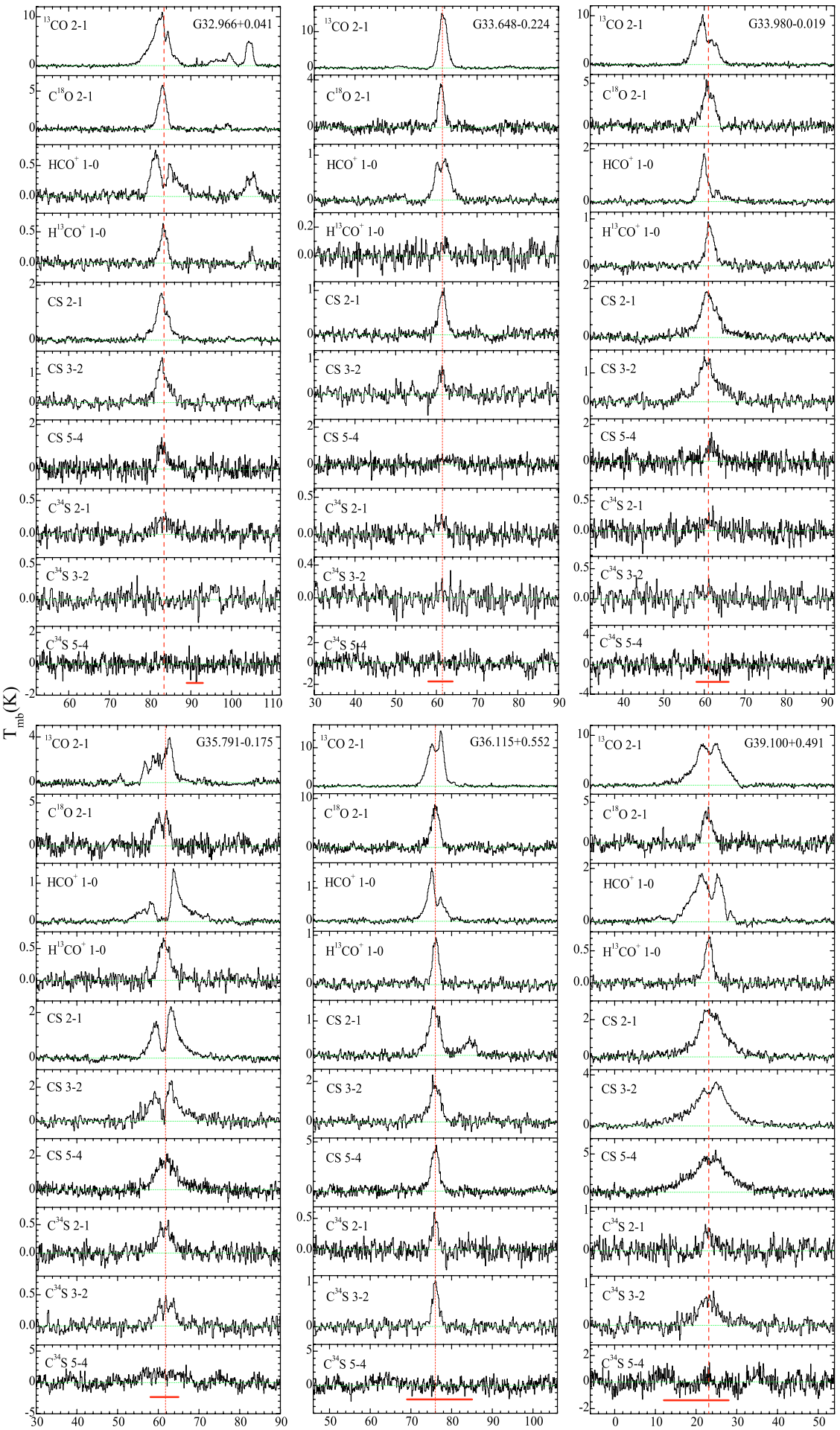

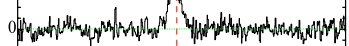

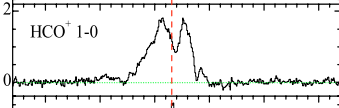

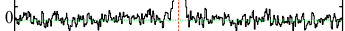

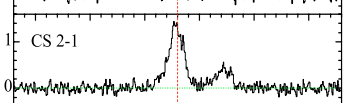

$.5=\mathrm{H}^{13} \mathrm{CO}^{+} 1-0$
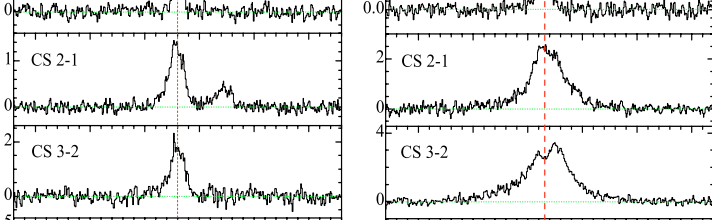

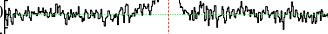

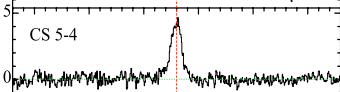

$0 . 5 \longdiv { C ^ { 3 4 } \leq 2 - 1 }$

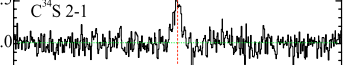



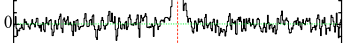

${ }^{5} \mathrm{C}^{34} \mathrm{~S} 5-4$

0.5.

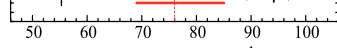

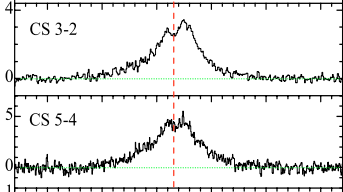

$C^{34} \mathrm{~S} 2-1$

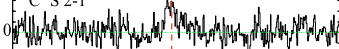

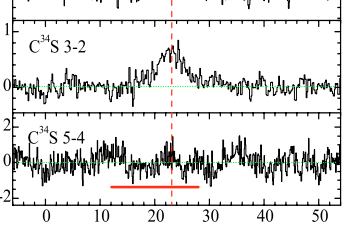

Velocity $\left(\mathrm{km} \mathrm{s}^{-1}\right)$

Fig. A.1. continued. 
M. Szymczak et al.: Molecular line study of high-mass protostars, Online Material $p 9$



Fig. A.1. continued. 
M. Szymczak et al.: Molecular line study of high-mass protostars, Online Material p 10
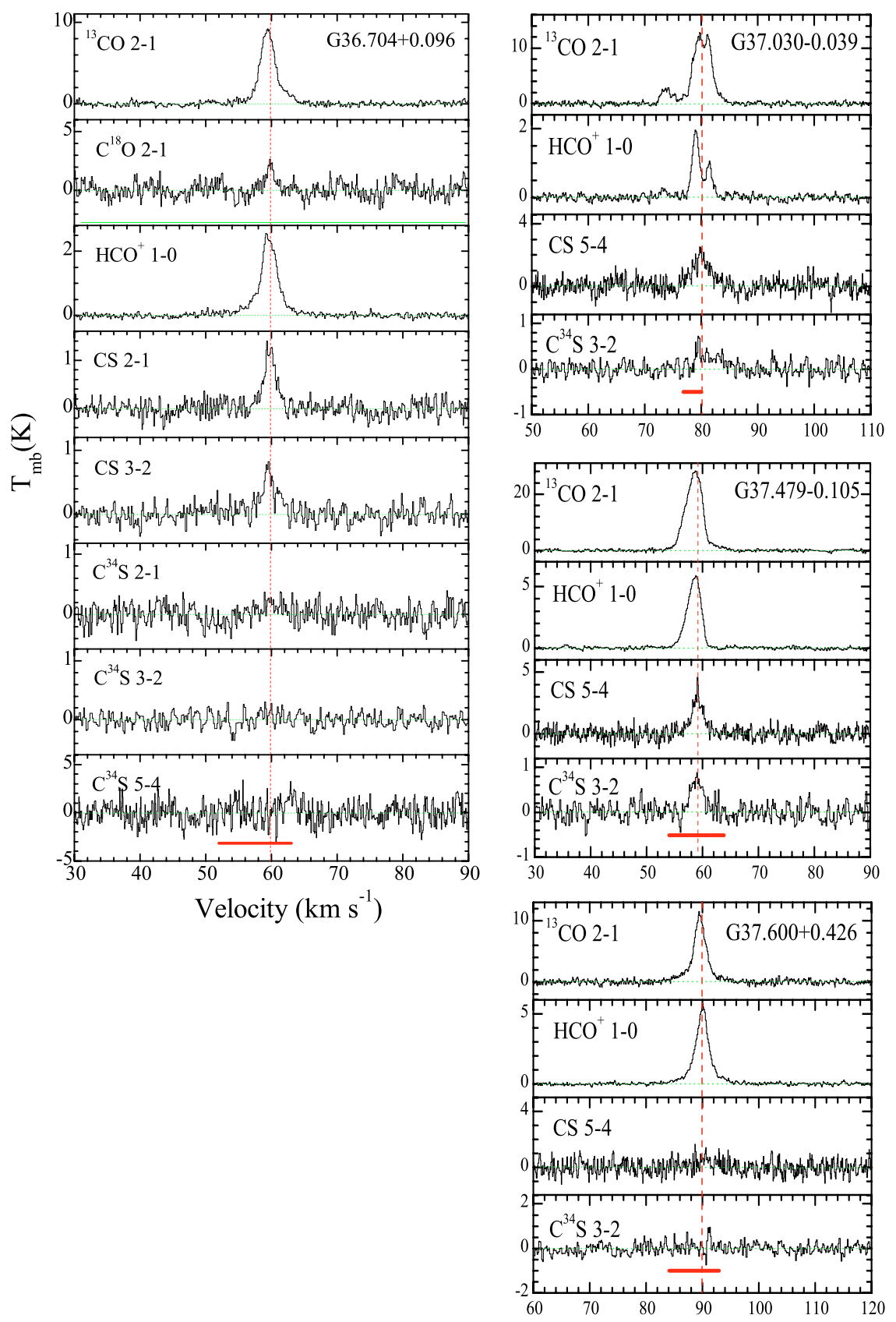

Fig. A.1. continued. 